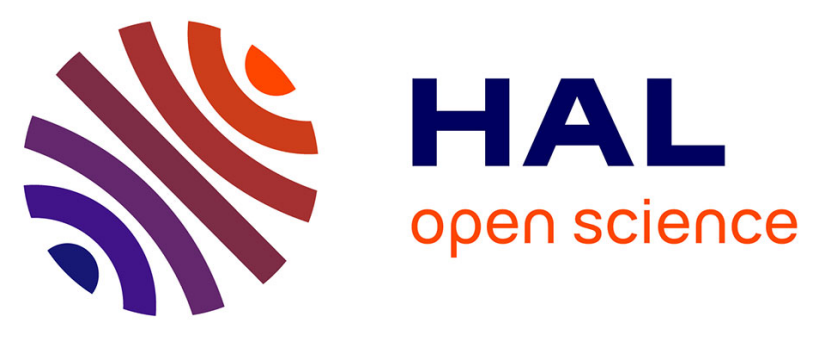

\title{
Influence of Blade Deformations on Open-Rotor Low-Speed and High-Speed Aerodynamics and Aeroacoustics
}

\author{
F. Falissard, R. Boisard, R. Gaveriaux, G. Delattre, P. Gardarein, A. Chelius, \\ S. Canard-Caruana, Y. Mauffrey
}

\section{To cite this version:}

F. Falissard, R. Boisard, R. Gaveriaux, G. Delattre, P. Gardarein, et al.. Influence of Blade Deformations on Open-Rotor Low-Speed and High-Speed Aerodynamics and Aeroacoustics. Journal of Aircraft, 2018, pp.1-15. 10.2514/1.C034676 . hal-01870952

\section{HAL Id: hal-01870952 https://hal.science/hal-01870952}

Submitted on 10 Sep 2018

HAL is a multi-disciplinary open access archive for the deposit and dissemination of scientific research documents, whether they are published or not. The documents may come from teaching and research institutions in France or abroad, or from public or private research centers.
L'archive ouverte pluridisciplinaire HAL, est destinée au dépôt et à la diffusion de documents scientifiques de niveau recherche, publiés ou non, émanant des établissements d'enseignement et de recherche français ou étrangers, des laboratoires publics ou privés. 


\title{
Influence of Blade Deformations on Open-Rotor
}

\section{Low-Speed and High-Speed Aerodynamics and Aeroacoustics}

\author{
F. Falissard*† R. Boisard; R. Gaveriaux, G. Delattre, P. Gardarein*; \\ ONERA - The French Aerospace Lab, Meudon, F-92190, France
}

\author{
A. Chelius, S. Canard-Caruana*, and Y. Mauffrey* \\ ONERA - The French Aerospace Lab, Châtillon, F-92322, France
}

This paper investigates by means of Computational Fluid Dynamics (CFD) and acoustic analogy the influence of blade deformations on open-rotor aerodynamics and aeroacoustics for three key operating points: cruise, takeoff and approach conditions. For each operating point, simulation results obtained with unrunning blade shapes and running blade shapes are compared with wind tunnel test measurements. Experiments show that blade deformations affects mostly the front rotor, with twist deviations at tip varying within a range of $\pm 2^{\circ}$ and of opposite sign between cruise and takeoff conditions. Although blade deformations are low for the rear rotor, aerodynamic performance exhibits significant variations due to the modifications of the front rotor wash. Numerical results show that accounting for blade deformations increases or decreases the thrust or power depending on the operating point and leads to a much better prediction of the open-rotor aerodynamic performance. The same comments apply for the noise prediction although differences on self noise and interaction noise directivities are rather low.

Presented as Paper 2017-3869 at the 23 ${ }^{\text {rd }}$ AIAA/CEAS Aeroacoustics Conference, Denver, CO, 5-9 June 2017. * Research Scientist, Aerodynamics, Aerolasticity, and Acoustics Department

${ }^{\dagger}$ Corresponding author, Fabrice.Falissard@onera.fr 


\section{Nomenclature}

$$
\begin{aligned}
& B=\text { rotor blade count } \\
& \mathrm{BPF}=\text { blade-passing frequency, } \mathrm{Hz} \\
& C_{P} \quad=P / \rho_{\infty} n^{3} D^{5}, \text { power coefficient } \\
& C_{T}=T / \rho_{\infty} n^{2} D^{4}, \text { thrust coefficient } \\
& D \quad=\quad \text { rotor diameter, } \mathrm{m} \\
& J \quad=\quad V_{\infty} / n D \text {, advance ratio } \\
& F, R=\text { front and rear rotors } \mathrm{BPF}, \mathrm{Hz} \\
& n=\omega / 2 \pi \text {, rotation fundamental, } \mathrm{Hz} \\
& P \quad=\text { power, } \mathrm{W} \\
& p \quad=\text { pressure, } \mathrm{Pa} \\
& R_{t}, R_{h}=\text { tip radius, hub radius, } \mathrm{m} \\
& T=\text { thrust, } \mathrm{N} \\
& V \quad=\quad \text { velocity, } \mathrm{m} \cdot \mathrm{s}^{-1} \\
& \beta=\text { blade pitch angle at } 0.7 R_{t}, \text { deg } \\
& \gamma=\text { ratio of gas specific heats } \\
& \eta=J C_{T} / C_{P}, \text { efficiency } \\
& \rho \quad=\text { density, } \mathrm{kg} \cdot \mathrm{m}^{-3} \\
& \Omega, \omega=\text { rotation speed, } \mathrm{rpm}, \mathrm{rad} . \mathrm{s}^{-1}
\end{aligned}
$$

\section{Subscripts}

$$
\begin{array}{ll}
1,2 & =\text { front, rear rotor value } \\
\infty & =\text { freestream value }
\end{array}
$$

\section{Introduction}

Counter-Rotating Open-Rotor engine architectures are currently under investigation as possible candidates to motorize next generation short and middle range civil aircrafts. In this context engine 
manufacturers, in collaboration with aircraft manufacturers and research centers, have designed and tested Open-Rotors geometries that would meet aerodynamic performance requirements with sufficient margin with respect to AESA and FAA noise regulations. These objectives were only met by fine tuning the design of open-rotor blades leading to high aspect ratio highly swept blades with thin airfoil sections ${ }^{1,2}$ and internal structures mostly relying on composite materials. Considering that open-rotor operate under high disk loading for flow conditions ranging from low-subsonic to transonic, the blades experience significant and complex deformations. ${ }^{3,4}$ Ideally, numerical simulations of open-rotor aiming at assessing aerodynamic and acoustic characteristics should account for these blade deformations. ${ }^{5,6}$ Yet, calculations on different operating points are often carried out considering the same geometry. ${ }^{7,8}$ This is the case when the blade structural model is not available, such as in the first stages of the design phase. Objective thrust or power are then achieved by adjusting the pitch angles of the front and rear rotor blades and the rotor rotation speed. Blade deformations are also rarely taken into account for computations aiming at studying the influence of aerodynamic or acoustic aircraft installation effects on global performances or near field and far field radiated noise. For this kind of analysis, the calculations use whether the design or manufactured blade geometries.

The objective of this paper is to quantify the error that is made on the assessment of aerodynamic performance, flow topology and acoustics of open-rotor when blade deformations are not take into account. This study focuses on three flight conditions for which open-rotor operating points are completely dissimilar from both aerodynamic and acoustic points of view: a cruise condition, characterized by moderate front and rear rotor thrusts, high tip Mach numbers, and high contribution of front and rear rotors self noise to the radiated noise; a take-off condition, characterized by high values of front and rear rotor thrusts, moderated tip Mach numbers, and high contribution of interaction noise to the radiated noise; an approach condition, characterized by low values of front and rear rotor thrusts, moderate tip Mach numbers, and high contribution of interaction noise to the radiated noise. The analysis rely on the use of Computational Fluid Dynamics (CFD) and acoustic analogy, based on the Ffowcs Williams and Hawkings (FWH) equation applied to the Airbus Clean Sky generic Open Rotor configuration AI-PX7 11x9 open rotor at 1/5th model 
scale. This geometry was tested during year 2013 in ONERA's S1MA transonic wind tunnel in the frame of the European Union 7th Framework Joint Technology Initiative (JTI) Smart Fixed Wing Aircraft Integrated Technology Demonstrator (SFWA ITD) project ${ }^{\mathrm{a}}$. For each operating point, simulations carried out considering the open rotor unrunning blade shapes and running blade shapes are compared to each other and with experimental measurements. The aim of the paper is thus to quantify the influence of accounting or not for blade deformations on the prediction of open rotor aerodynamic and acoustic performance.

The paper is organized as follows: the open rotor geometry and operating points are presented in section II; the computational methodologies used for the evaluation of open rotor aerodynamics and acoustics are detailed in section III. The results of the computations carried out for the study, covering blade deformations, aerodynamics performance, flow topology and acoustics, are presented and discussed in section IV.

\section{Open-Rotor Geometry and Operating Points}

The open-rotor geometry considered in this study is the Airbus Clean Sky generic Open Rotor configuration AI-PX7 11x9 open rotor that is thoroughly described in Ref. [1]. The main characteristics of this open-rotor at full scale are reminded in table 1. The model scale open-rotor that was tested in ONERA's S1MA transonic wind tunnel, referred to hereafter as Z49 open-rotor, was mounted on ONERA's BHCR ${ }^{\mathrm{b}}$ test-rig dedicated to open-rotor studies whose instrumentation allows measuring open-rotor overall performances, blade pressures, near-field and far-field acoustics as well as blade deformations. The present tests and rig development (including the acoustic beam) were performed as a cooperation betwen Airbus Operations SAS and ONERA. Detailed descriptions of the test rig aerodynamic and acoustic measurement capabilities can be found in Refs. [9-11]. Illustrations of the wind tunnel, test-rig installation within the test section and test rig with open-rotor and near-field acoustic beam are given in Figures 1 and 2.

The scope of the present study is to assess the influence of blade deformations on AI-PX7

\footnotetext{
${ }^{a}$ http://www.cleansky.eu/content/page/sfwa-smart-fixed-wing-aircraft

b'Banc d'essais d'Hélices ContraRotatives, i.e. open-rotor test rig
} 
Z49 open-rotor aerodynamics and aeroacoustics for operating points encountered by an open-rotor during a typical flight mission. For this purpose, two low-speed conditions (take-off and approach) and one high-speed condition (nominal cruise) have been chosen among the many operating points that have been measured during the wind tunnel test campaign. The freestream parameters and the open-rotor operating conditions corresponding to these three wind-tunnel test measurements are summarized in table 2.

Table 1. AI-PX7 open-rotor characteristics. ${ }^{1}$

\begin{tabular}{lc}
\hline \hline Parameter & Value \\
\hline Front rotor blades, $B_{1}$ & 11 \\
Rear rotor blades, $B_{2}$ & 9 \\
Front rotor tip radius, $R_{t}[\mathrm{~m}]$ & 2.134 \\
Hub-to-tip ratio, $R_{h} / R_{t}$ & 0.35 \\
Rear rotor cropping & $10 \%$ \\
Rotor-rotor axial spacing, $x / D$ & 0.22 \\
\hline \hline
\end{tabular}

Table 2. AI-PX7 Z49 open-rotor operating points.

\begin{tabular}{lccc}
\hline \hline & Cruise & Takeoff & Approach \\
\hline Mach number, $M_{\infty}$ & 0.75 & 0.2 & 0.2 \\
Angle of incidence $\left[^{\circ}\right]$ & 0 & 0 & 0 \\
Air temperature $[\mathrm{K}]$ & 284.7 & 304.8 & 304.5 \\
Air pressure [Pa] & 61,758 & 87,090 & 87,080 \\
Rotation speed $[\mathrm{Hz}]$ & 75.1 & 84.5 & 57.5 \\
Advance ratio $^{\mathrm{a}}, J$ & 3.957 & 0.971 & 1.427 \\
${\text { Front blade pitch, } \beta_{1}[\mathrm{deg}]} \mathrm{63.0}$ & 37.0 & 37.0 \\
Rear blade pitch, $\beta_{2}[\mathrm{deg}]$ & 62.5 & 40.0 & 40.0 \\
\hline \hline
\end{tabular}

\section{Computational Methodology}

In order to quantify the influence of blade deformation on AI-PX7 Z49 open-rotor aerodynamics and acoustics, two simulations are performed for each operating point: the first one considering 
the unrunning CAD (Computer-aided design) blade geometry, the second one considering the timeaveraged running blade shapes measured during the experiment. The unrunning and running blade geometries do not take into account manufacturing defects, discussed in Ref. [11], which make each blade slightly different. The computational method used here to assess the AI-PX7 Z49 openrotor aerodynamics and acoustics relies on the coupling of computational fluid dynamics (CFD) and integral methods based on the acoustic analogy. ONERAs methodology is based on the $e \mathrm{ls}^{12}$ and $\mathrm{KIM}^{13}$ solvers, that have been widely used for open-rotor characterization and optimization. ${ }^{14-22}$ Cassiopee $^{23}$ is used for pre- and post-processing of the computations.

\section{III.A. Computed Geometry and Mesh Generation}

The AI-PX7 Z49 simplified geometry used for numerical simulations is presented in Figure 3. It accounts for open-rotor minimum body spinner and nacelle, the rotating front rotor and hub, the rotating rear rotor and hub, and finally the sting of the BHCR test-rig up to $x / D=3.5$ downstream the rear rotor. This simplified geometry does not account for gaps between the rotating hubs nor for gaps at the junctions between the rotor blades and hubs.

Since the operating points detailed in table 2 exhibit no incidence, the flow solutions are expected to be axisymmetric. Accordingly, only one blade channel of the front and rear rotor need to be discretized which allows the use of fine grids for relatively moderate computational costs. The computational grids, displayed in Figure 4, consist in a full matching structured multi-block mesh generated using ANSYS ICEM CFD Hexa mesh generation software. The computational domain extends 7 radii upstream and downstream of the rear rotor pitch axis and 4 radii in the radial direction. The grid topology is the same as the one used in Ref. [11], with O-grid mesh types around solid surfaces to avoid spreading boundary layer mesh refinement toward outer boundaries. The rotor blades are discretized with 201 grid points per side in the chordwise direction, with 41 grid points on the blunt trailing edge. In the spanwise direction, the front and rear rotor blades are discretized respectively with 121 and 113 grid points. The average azimuthal density of the grids at the interface between the front and rear rotors computational domains is of 3.7 grid points per degree upstream to the interface and of 6.2 grid points per degree downstream to the interface. 
The complete computational grid consist in 31.4 million cells and 326 structured blocks leading to a approximately 34 million grid points. For this $11 \times 9$ bladed open rotor configuration, this corresponds to a full 360 grid discretization of about 307.8 million cells.

Following the methodology developed in Ref. [11], the meshing is done on the unrunning CAD geometry only, the grid for the running shape calculations is generated by deforming the unrunning shape mesh using the experimental blade deformations resulting from the strain pattern analysis (SPA) method described in Ref. [24]. CFD mesh deformations are performed using a structural analogy algorithm. ${ }^{25}$ First a linear structural problem is solved on a coarser mesh, defined by packing several cells in each directions, then a linear interpolation is performed to get the displacements on all points of the CFD mesh. In the frame of multiblock-structured mesh discretization, the mesh coarsening could lead to non-matching grid interfaces, this is prevented by using a mortar finite element method ${ }^{26}$ to solve the linear structural problem in parallel. Comparing minimum and maximum values of cells volume and orthogonality between initial and deformed CFD meshes, given in Tab. 3, show that this method does not decrease the quality of the initial grid.

\begin{tabular}{lccc} 
Table 3. Variations of cell properties between initial and deformed CFD meshe \\
\hline \hline & Cruise & Takeoff & Approach \\
\hline Min. volume & $+3.89 \%$ & $-0.17 \%$ & $-0.04 \%$ \\
Max. volume & $+0.00 \%$ & $+0.00 \%$ & $+0.00 \%$ \\
Min. orthogonality & $+0.00 \%$ & $-0.19 \%$ & $+0.09 \%$ \\
Max. orthogonality & $-0.16 \%$ & $+2.40 \%$ & $+0.03 \%$ \\
\hline \hline
\end{tabular}

\section{III.B. Computational Fluid Dynamics Simulation Setup}

The CFD computations, solving the steady or unsteady compressible Reynolds-averaged NavierStokes equations, are carried out considering one blade channel only. Unsteady computations are performed using a phase/lag chrorochronic approach ${ }^{27,28}$ and are initialized by the steady solution obtained using a mixing plane approach. The numerical setup is similar to the one presented in Ref. [11] and benefits from ONERA's best practices for open-rotor simulations.

The turbulence modeling relies on a $k-\omega$ turbulence model ${ }^{29}$ with shear-stress transport (SST) 
correction $^{30}$ and limiters. ${ }^{31}$ The convective and diffusive fluxes are discretized using a second-order centered scheme with scalar artificial viscosity ${ }^{32}$ and Martinelli's correction. ${ }^{33}$ The coefficient of the second-order non-linear, fourth order linear dissipations and Martinelli's scaling exponent are set respectively to $\kappa^{(2)}=1 / 2, \kappa^{(4)}=4 / 125$ and $\alpha=1 / 3$. The computations are carried out considering an absolute velocity formulation within the relative reference frame. Characteristic relation based flow boundary conditions are used at the domain inlet, outlet and radial boundary with infinite flow values corresponding to the ones given in Tab. 2. All solid surfaces were considered as adiabatic walls using a low Reynolds approach. The time-marching scheme used for the steady computations is first-order backward Euler scheme while for unsteady computations it is a secondorder three-time-level implicit backward-difference scheme ${ }^{34}$ solved by a Newton algorithm. For all unsteady computations, the physical time-step corresponds to an azimuthal angle equal to $2 / 11$ deg leading to 1980 iterations per full revolution. For the $11 \times 9$ bladed AI-PX7 Z49 open-rotor, this corresponds to a crossing period of 110 time-steps for a front rotor blade and 90 time-steps for a rear rotor blade. For each time iteration, the maximum number of Newton sub-iterations was set to 25. Convergence of the chrorochronic flow solution is obtained after 2.5 revolutions corresponding to 45 front and 55 rear blade chorochronic periods. The unsteady aerodynamic data necessary for the acoustic computations are extracted every iterations, $i$. e. every $0.1818^{\circ}$.

\section{III.C. Noise Radiation Computations}

The noise radiated by the open rotor is computed with ONERA's code KIM, ${ }^{13}$ which solves the Ffowcs Williams and Hawkings (FWH) equation ${ }^{35}$ in the temporal domain and considering a uniform free-stream propagation medium. Both solid and porous surfaces formulations of the FWH equation are implemented in KIM. The porous one is actually best suited to quantify the noise directivities of open rotors as it accounts for all sources as well as non uniform propagation and flow gradients embedded within the porous surface. Ideally that surface should be located close enough to the rotors to collect (or capture) the aerodynamic fields with minimum numerical dissipation and dispersion, but far enough to encompass the main flow in-homogeneities.

Finding a common surface satisfying these requirements for the three operating points ad- 
dressed in this study is not straightforward. To do so, the radiated noise has been computed using several porous surfaces with different radii. In a first step, we select the closest surface for which a convergence is obtained on the directivities of the first harmonics of the front and rear rotor self noise for the cruise operating point. This ensures that sufficiently quadruple source terms are accounted for to obtain a good prediction of the global noise level. ${ }^{16}$ In a second step, we verify that this surface is also close enough to predict correctly the self noise of the open rotor for the two other operating points. The selected surface is shown in Figure 5, it has a radius of $1.21 R_{t}$. It has to be noted that in our methodology, the porous surface is closed downstream to the open rotor. The FWH porous formulation we use contains specific additional terms to handle properly the passage of vortical structures, ${ }^{36,37}$ yet some effects cannot be reproduced such as refraction and scattering of the downstream acoustic waves by the shear layer separating the open rotor wake and the external flow. ${ }^{19}$

The full conservative variables are extracted on the porous surface over a blade crossing period, and reconstructed in space and time over $360^{\circ}$ and one revolution in the rotating frame. The noise radiated by the open rotor is then obtained by summing the temporal acoustic signatures of the front and rear parts of the surface. 


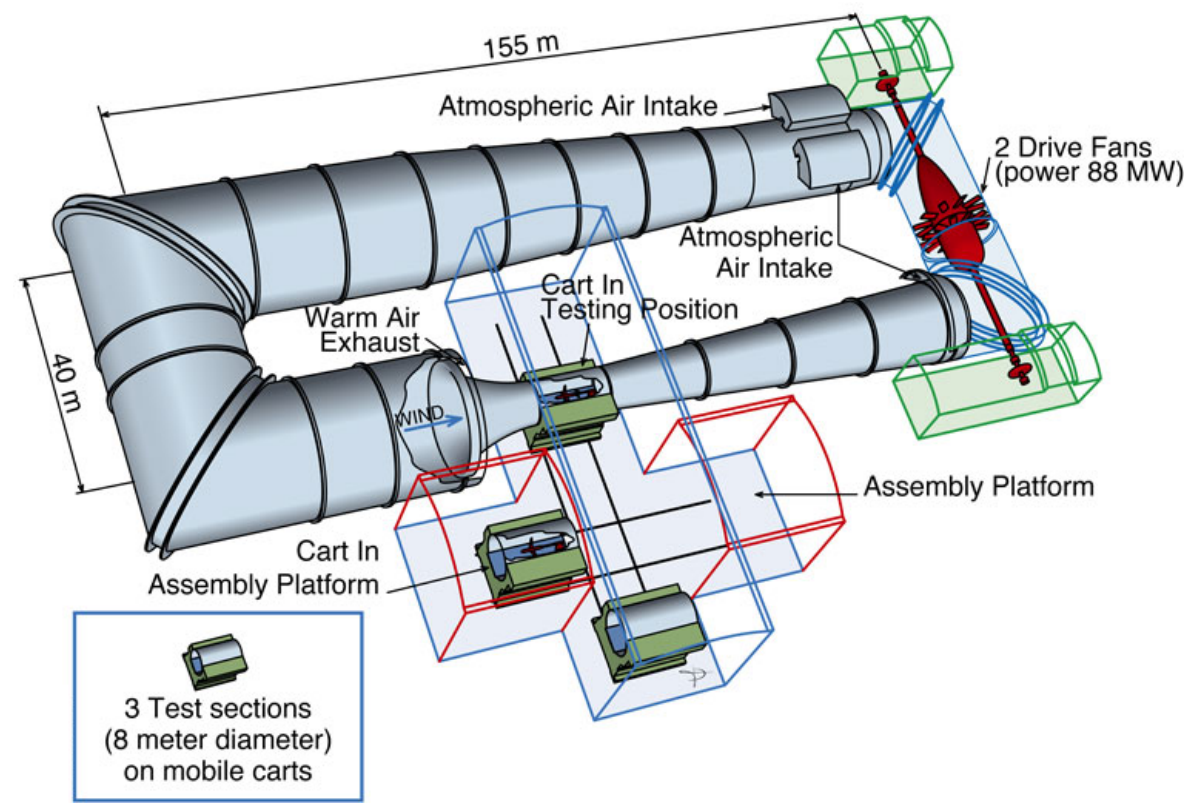

(a) ONERA's S1MA wind tunnel

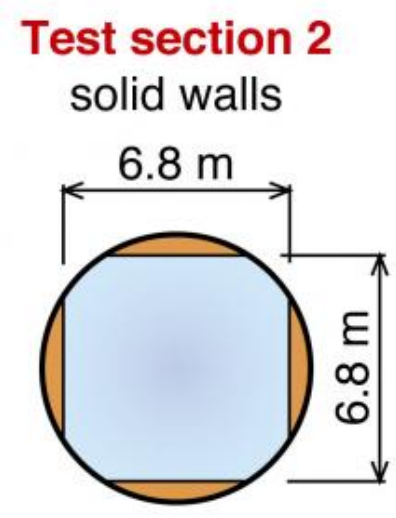

$45.4 \mathrm{~m}^{2}$ test section

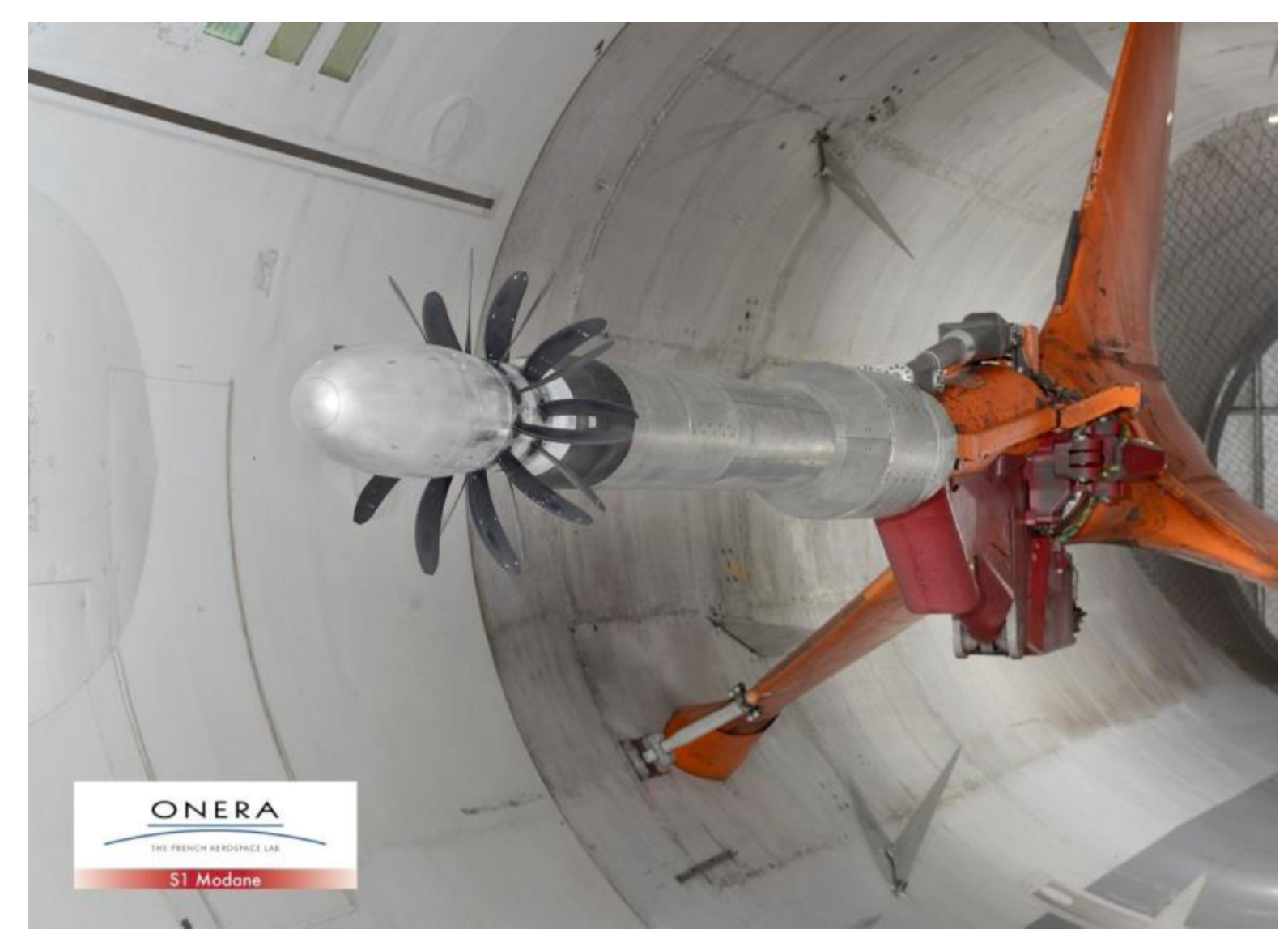

(c) Rig in test section

Figure 1. ONERA's S1MA wind tunnel and BHCR open-rotor test-rig used for AI-PX7 Z49 wind tunnel measurements. 


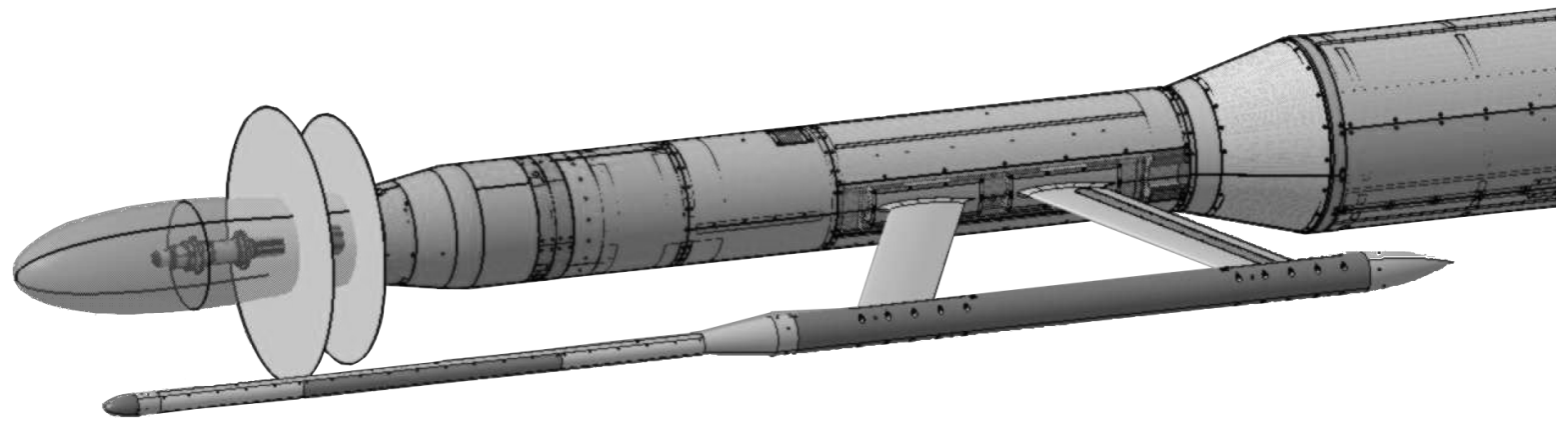

Figure 2. ONERA's BHCR open-rotor test-rig with acoustic beam used for AI-PX7 Z49 wind tunnel measurements. ${ }^{10}$

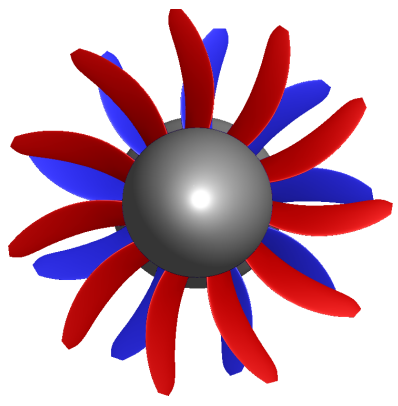

(a) Front view

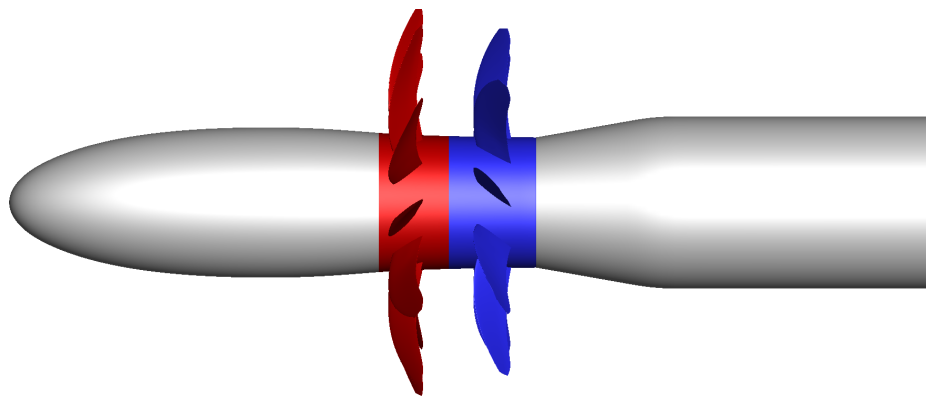

(b) Side view

Figure 3. AI-PX7 Z49 simplified geometry used for CFD computations with rotating parts highlighted.

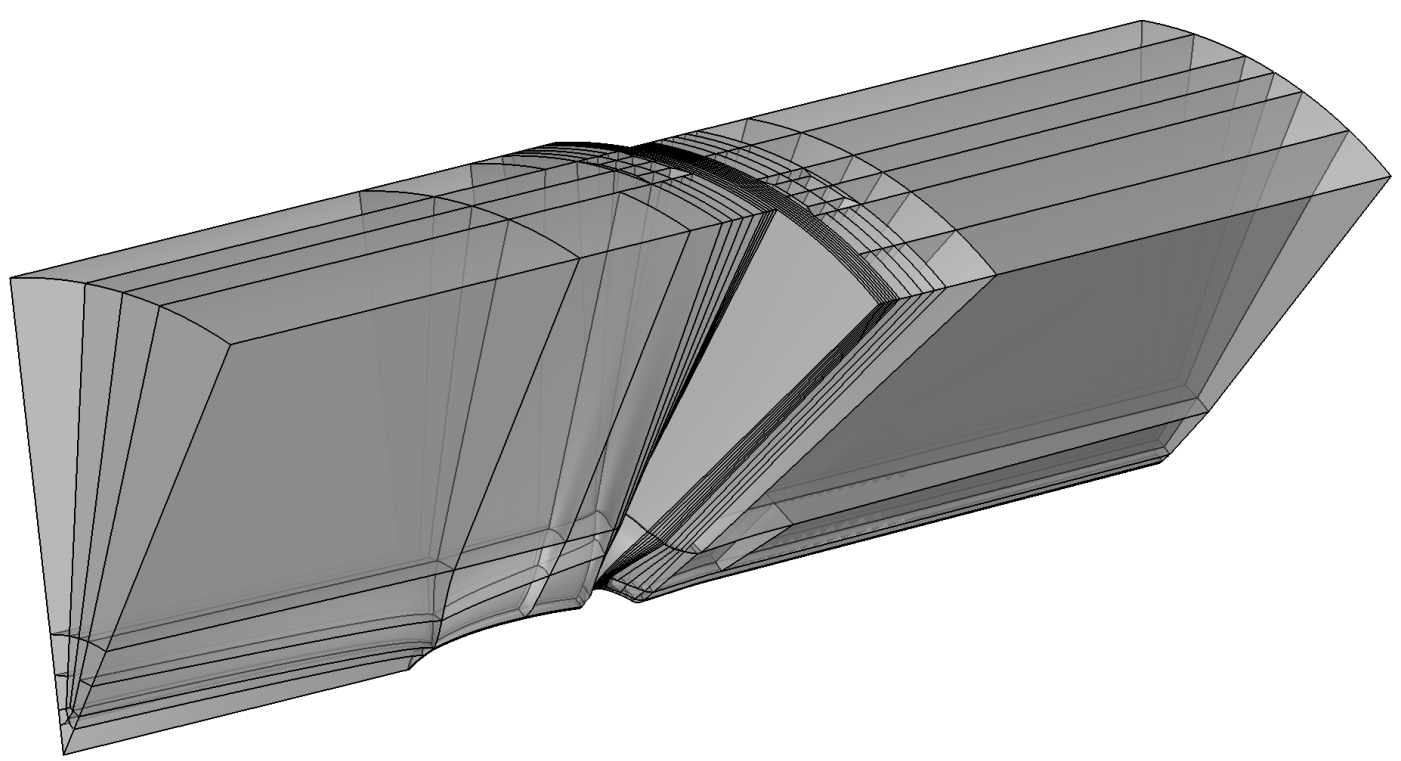

Figure 4. Grids of front and rear rotor single channels used for phase-lag CFD computations. 

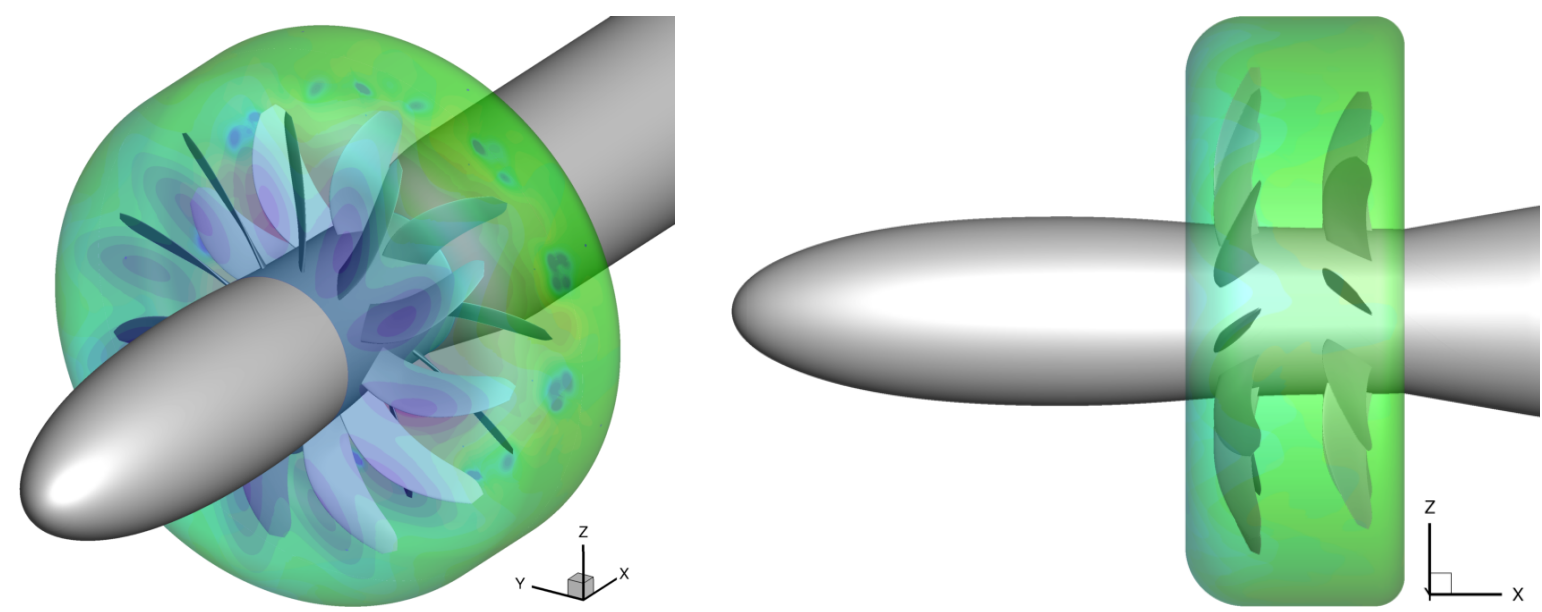

Figure 5. Isometric (left) and side (right) views of the FWH porous surface used for the aeroacoustic computations. 


\section{Results}

The results presented hereafter are divided in sections addressing different topics such as blade deformations, aerodynamic performance, flow topology, unsteady loads and aeroacoustics. Considering that analyzes of Open-Rotor flow characteristics found in the literature usually address one specific operating point, we choose to present simultaneously the results for all operating points so as to highlight the influence of accounting or not for blade deformations as well as to put forward the differences between these three key operating points.

\section{IV.A. Blade deformations}

The blades running shapes used in this study are obtained by applying to the unrunning shape the strain pattern analysis (SPA) method described in Ref. [24]. The strain gauges are embedded in the blade structure with adequate locations so as to maximize the accuracy of the blade deflection measurements. The main constraints on strain gauges positioning are the number of recorded channels available on the test rig, and the embedding of the gauges within the carbon layers. Thanks to an important calibration phase to determine modal shapes and modal strains, the blade deflection is determined as a function of time using the strains recorded during experiment. Due to the limited number of gauges available, only three modes were used to reconstruct the front blade and five modes for the rear blade. Details of the calibration, position optimization and validation of the SPA method used in this experiment are given in Ref. [24]. The spanwise distribution of twist, sweep and dihedral of the front and rear rotor blades running shapes are compared to the ones of the blade unrunning shapes in Fig. 6. It has to be noted that none of the geometries shown here match exactly the original design of the AI-PX7 given in Ref. [1] and that the unrunning shapes at $1 / 5^{\text {th }}$ scale were derived in preparation of the high-speed wind tunnel tests ${ }^{6}$ within a dedicated task of the JTI SFWA project.

The greatest deformations of the front and rear rotor blades are obtained for the high-speed cruise operating point, especially on the front rotor which has a much higher aspect ratio than the

rear one. The balancing of centrifugal, Coriolis and aerodynamic forces results in a significant 
increase of the blade twist and dihedral from the blade middle section up to the tip. The front blade twist angle is increased by $2^{\circ}$ at the tip, which is significant for this transonic operating point. Since inertial forces lead usually to a decrease of both the twist and dihedral, this indicates that aerodynamic loads are predominant and opposite to inertial forces for these composite blades. It is worthy of note that the geometric span laws of the running blades are close to the original design, especially on the twist laws that match very well the arctangent of the design freestream and rotating velocities for both rotors. ${ }^{1}$ This highlight the quality of the methodology used to derive the unrunning shape and indicates that the original design and measured running blade shapes would give similar results.

The second operating point exhibiting significant blade deformations is the takeoff condition. As for the cruise operating point, the front blade is more affected than the rear blade. This is again due to its higher aspect ratio. The rotation speed of the rotors is about $10 \%$ higher than for the nominal cruise but we still observe an increase of the blade bending. Yet, the front blade twist is now decreased toward the tip indicating that load repartitions with respect to the blade section are completely different in this region. The front running blade twist angle at tip is now decreased by $1.8^{\circ}$ compared to the unrunning geometry leading to a decrease of $3.8^{\circ}$ compared to the high-speed running shape.

Finally, the running blade shapes for the approach operating point are very similar to the unrunning blade shapes. The rotation speed of the rotors is about $20 \%$ slower than for the cruise condition reducing significantly inertial forces. The twist and dihedral of the front rotor blades are slightly modified at the tip and the shapes of the running rear rotor blades are very close to the unrunning geometry. 
Front rotor blade
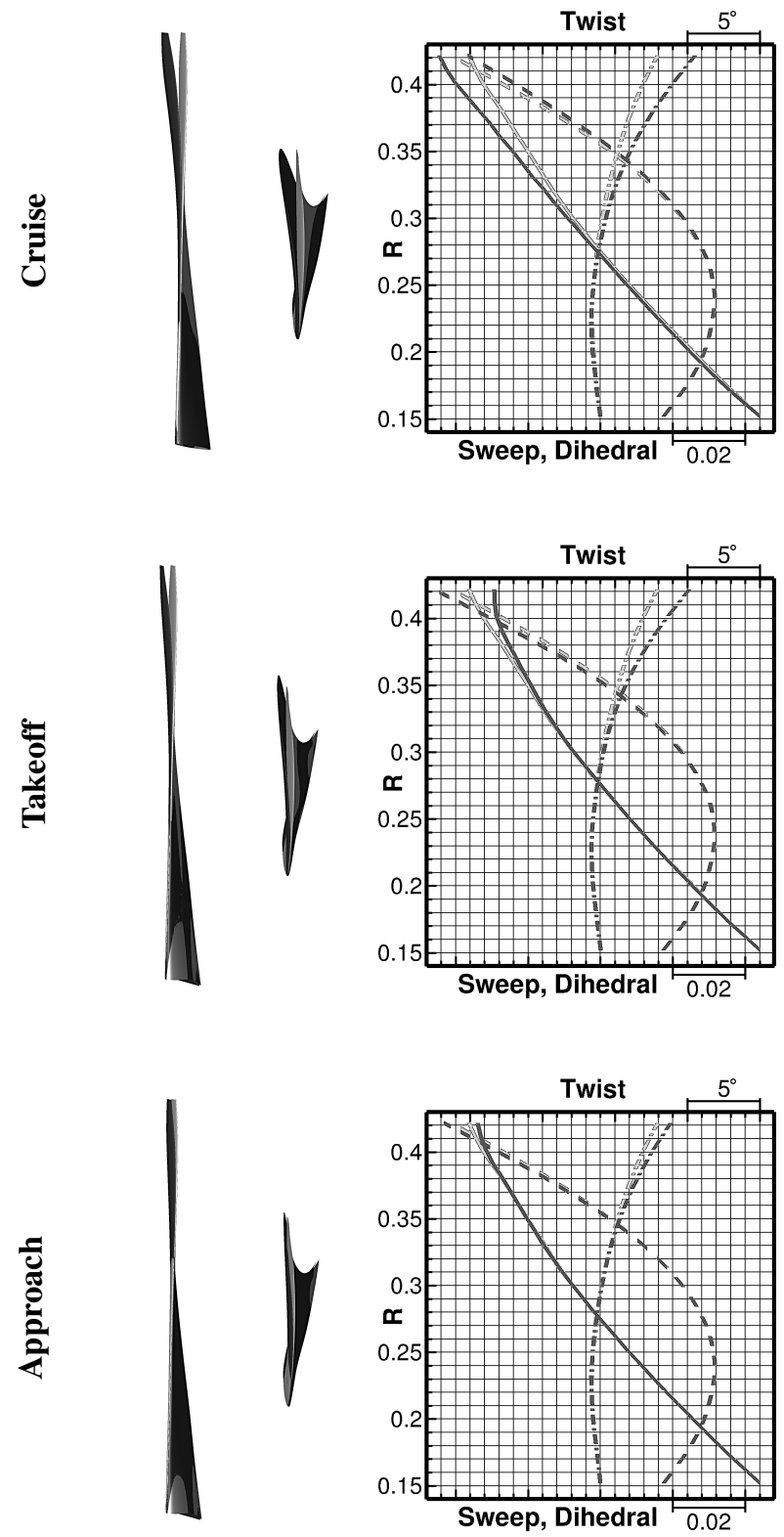

Rear rotor blade
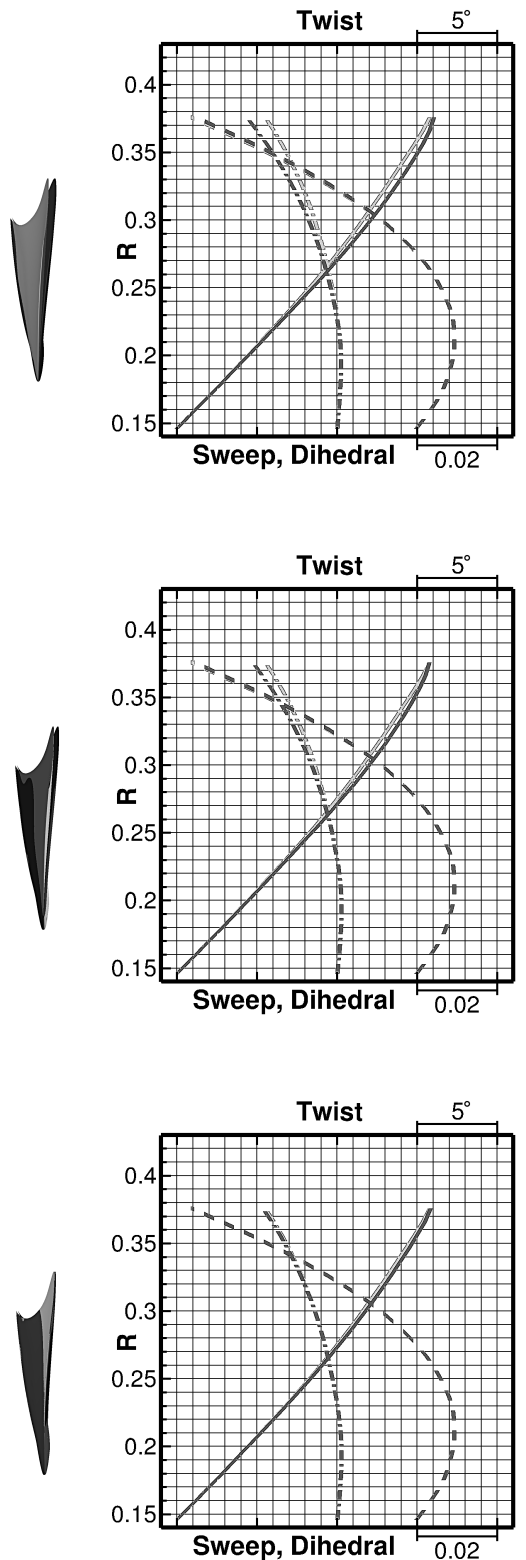

Unrunning shape: twist (-), sweep (--), dihedral (- - -). Running shape: twist (-), sweep (--), dihedral ($\cdot-)$.

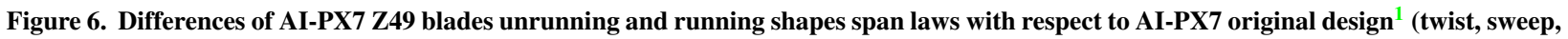
and dihedral) for cruise, takeoff, and approach operating points. 


\section{IV.B. Aerodynamic performance}

The unsteady CFD simulations have been carried out on the running and unrunning geometries for the three operating points using the computational grids and setup presented in section III. The CFD simulations are compared to the experiments using classical thrust coefficient $\left(C_{T}\right)$, power coefficient $\left(C_{P}\right)$, and efficiency $(\eta)$ that are defined as:

$$
C_{T}=\frac{T}{\rho_{\infty} n^{2} D^{4}}, \quad C_{P}=\frac{P}{\rho_{\infty} n^{3} D^{5}}, \quad \eta=\frac{J C_{T}}{C_{P}}
$$

where $T$ and $P$ are the thrust and power respectively produced and consumed by the rotor, $J=$ $V_{\infty} / n . D$ is the advance ratio, $\rho_{\infty}$ is the air density of the upstream flow, $n$ and $D$ are the rotation frequency and the rotor diameter. The front rotor, rear rotor and open-rotor aerodynamic performance of the unrunning and running shapes simulations are compared to experimental measurements in Tab. 4. Experimental cruise and takeoff conditions exhibit high values of thrust coefficients. For the cruise condition, the rear rotor produces more thrust than the front rotor. The opposite happens for the takeoff condition. The thrust coefficient for the approach condition is about half the value of the two other operating points. Yet, it has to be kept in mind that these coefficients are made non dimensional using the different freestream values and rotation speeds given in Tab. 2. Actually, the thrust produced at takeoff and approach are equivalent respectively to $170 \%$ and $40 \%$ of the thrust produced at cruise. Consequently, the disk loading is extremely high at takeoff condition. Regarding power consumption, the highest value is obtained for the cruise condition but efficiency is very high for this point thanks to high value of the advance ratio. The value of $C_{P}$ at takeoff is about 2.6 lower but combined with an equivalent value of $C_{T}$ and a much lower value of $J$ this results in an efficiency of only 0.59 , typical of highly loaded propellers at low-speed. For the approach condition, the ratio $C_{P}$ over $C_{T}$ is close to the one of the takeoff condition but the higher value of $J$ results in a correct efficiency of 0.77 . In terms of effective power consumption, takeoff and approach conditions are equivalent respectively to $71 \%$ and $13 \%$ of the power needed for the cruise operating point. Aerodynamic performances predicted by CFD calculations based on

unrunning and running blade shapes will now be compared with these experimental values. Note 
the coefficients from the CFD calculations have been obtained by averaging their unsteady values over the last revolution.

For the cruise operating point, the thrust and power coefficients of CFD solutions with running blade shapes are much closer to the experiments than the solution obtained with the unrunning shape. Considering the full open-rotor, the error of the running shape solution is four times smaller than the error of the unrunning shape simulation. Yet, this trend is not observed on the efficiency since it involves the ratio of $C_{T}$ and $C_{P}$ such that large (respectively small) errors may compensate (respectively worsen) each other. Comparing the running and unrunning simulations, the increase of twist of the front blade running shape, described in the previous section, reduces about $5 \%$ the thrust and power compared to the unrunning geometry. This was to be expected since in the frame attached to the airfoil, reducing the pitch at constant advance ratio results in a decrease of the local incidence and probably an increase of lift to drag ratio in this transonic regime. Thrust and power of the rear rotor are also diminished for the running blade shape but this effect cannot be related only to the local pitch variation since decreasing the front rotor thrust also lessen the upstream velocity seen by the rear rotor.

For the takeoff operating point, thrust and power coefficients of CFD solutions with running blade shapes are closer to the experimental value for the front rotor than with unrunning blade shapes, but the opposite trend is observed for the rear rotor. When considering the full open-rotor, the error of the running shape solution is again four times smaller than the error of the unrunning shape simulation. Comparing the running and unrunning simulations, the decrease of twist of the front blade running shape in the tip region is consistent with the increase of thrust compared to the front rotor unrunning shape. This increase of the front rotor thrust augments the speed of the upstream flow seen by the rear rotor. Combining this effect with the slight increase of twist of the rear blade running shape explains the decrease of rear rotor thrust when compared to the unrunning geometry.

For the approach operating point, the power coefficients of the running shapes calculations are closer to the experiment than the unrunning shapes calculations while the opposite happens when the thrust coefficients are considered. Taking into account the fact that blade deformations are very 
small for this low loaded operating point, it is difficult to highlight any specific trend.

Table 4. Time-averaged open-rotor performance for cruise, takeoff and approach operating points.

\begin{tabular}{|c|c|c|c|c|c|c|c|c|c|c|}
\hline & \multirow{2}{*}{ Results $^{b}$} & \multicolumn{3}{|c|}{ Front rotor } & \multicolumn{3}{|c|}{ Rear rotor } & \multicolumn{3}{|c|}{ Open rotor } \\
\hline & & $C_{T_{1}}$ & $C_{P_{1}}$ & $\eta_{1}$ & $C_{T_{2}}$ & $C_{P_{2}}$ & $\eta_{2}$ & $C_{T}$ & $C_{P}$ & $\eta$ \\
\hline \multirow{3}{*}{ 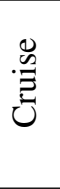 } & Experiments & 0.439 & 2.230 & 0.779 & 0.467 & 1.853 & 0.997 & 0.907 & 4.083 & 0.878 \\
\hline & CFD unrunning & $+11.1 \%$ & $+9.8 \%$ & $+1.3 \%$ & $+3.9 \%$ & $+6.4 \%$ & $-2.2 \%$ & $+7.4 \%$ & $+8.2 \%$ & $-0.7 \%$ \\
\hline & CFD running & $+5.3 \%$ & $+4.0 \%$ & $+1.3 \%$ & $-2.4 \%$ & $+0.2 \%$ & $-2.5 \%$ & $+1.3 \%$ & $+2.3 \%$ & $-0.9 \%$ \\
\hline \multirow{3}{*}{ 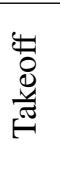 } & Experiments & 0.511 & 0.859 & 0.578 & 0.429 & 0.694 & 0.600 & 0.940 & 1.552 & 0.588 \\
\hline & CFD unrunning & $-3.6 \%$ & $-4.6 \%$ & $+1.0 \%$ & $-0.7 \%$ & $+0.5 \%$ & $-1.2 \%$ & $-2.3 \%$ & $-2.3 \%$ & $+0.0 \%$ \\
\hline & CFD running & $+1.0 \%$ & $+2.3 \%$ & $-1.3 \%$ & $-2.4 \%$ & $-1.7 \%$ & $-0.7 \%$ & $-0.6 \%$ & $+0.5 \%$ & $-1.1 \%$ \\
\hline \multirow{3}{*}{ 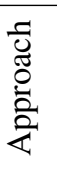 } & Experiments & 0.263 & 0.518 & 0.724 & 0.223 & 0.387 & 0.824 & 0.486 & 0.905 & 0.766 \\
\hline & CFD unrunning & $+1.2 \%$ & $-5.3 \%$ & $+6.8 \%$ & $-1.4 \%$ & $+1.3 \%$ & $-2.8 \%$ & $+0.0 \%$ & $-2.5 \%$ & $+2.5 \%$ \\
\hline & CFD running & $+4.5 \%$ & $-1.9 \%$ & $+6.4 \%$ & $-3.1 \%$ & $-0.6 \%$ & $-2.7 \%$ & $+1.0 \%$ & $-1.4 \%$ & $+2.3 \%$ \\
\hline
\end{tabular}

${ }^{b}$ based on front rotor diameter

\section{IV.C. Flow topology}

The influence of blade deformation on the flow topology is analyzed through wall pressure and friction lines, displayed in Fig. 7, and wall pressure coefficients extracted at different span positions along the blades, as shown in Fig. 8.

For the cruise operating point, wall pressure, friction lines and wall pressure coefficients are almost identical for blade span locations at which blade deformation is not major, typically for radii lower than $60 \%$ of the blade radius. For higher span locations, the flow over the front and rear blades are noticeably different on the running and unrunning geometries. On the front blade, the twisting of the blade under aerodynamic loads decreases the depressure at the tip and leading edge while the shock location is moved downstream. Although deformations are less important on the rear blade, significant differences are also observed on the pressure distribution. Actually, the modification of the front rotor wash seems to diminish the incidence on the upper section of the rear blade, thus increasing the pressure on the suction side near the leading edge and moving 
the shock downstream. Comparing the wall pressure coefficients of the two computations with the experimental measurements shows that the running shape calculation is closer to the experiments and that the blade deformations around the blade tip tend to unload the blade leading edge and to increase the load in the aft area of the blade sections due to the shock displacement. In Refs. [11,38], it has been shown that the results could be further improved, especially at blade root sections, by using even more accurate blade shapes accounting for local surface defects due to the manufacturing process.

For the takeoff operating point, both running and unrunning shapes exhibit strong flow separation along the blade leading edge. This flow separation, previously observed on AI-PX7 in Ref. [39], is typical of highly swept propellers for high loads operating point at low speed and contributes to the radiated tonal ${ }^{21,22}$ and broadband ${ }^{40}$ noise. Contrarily to the cruise operating point, the flow is now highly three-dimensional due to the separation at the front and rear blade leading edges. The location of the reattachment line depends on the blade sweep, twist and thrust. ${ }^{21}$ On the front blade, the flows are very similar for the running and unrunning shapes. An explanation might be that the sweep and twist variation of the running blade compensate each other with respect to the flow sensitivity. This tends to be confirmed by the similarity of the wall pressure coefficients. This is not the case on the rear blade since the running geometry exhibits a leading edge vortex much closer to the blade leading edge. This change of topology is verified on the wall pressure coefficients that have steeper slopes in the vicinity of the leading edge for span locations higher than $60 \%$ of the blade radius.

Finally, for the approach operating point, the flow is subsonic and quasi-bidimensional all over the front and rear rotor blades. No major differences are observed between the flows over the running and unrunning shapes due to their strong geometrical similarity. The same comment applies to the wall pressure coefficients extracted along the span of the front and rear rotor blades. 
Front rotor blade
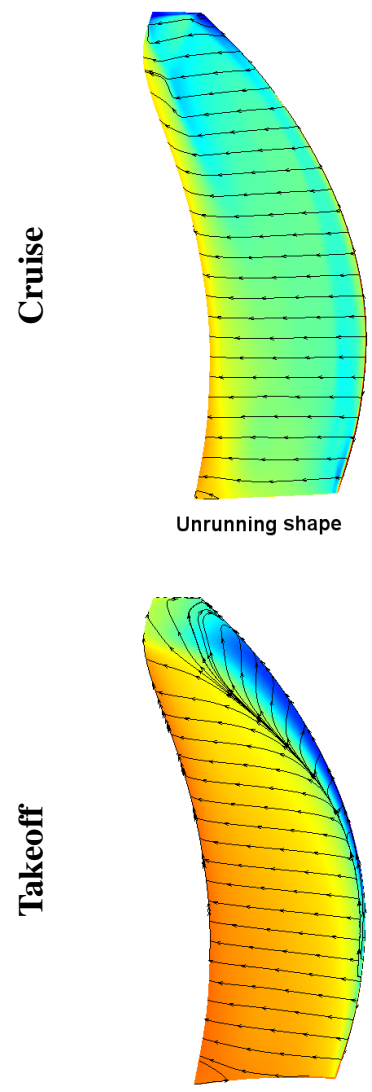

Unrunning shape

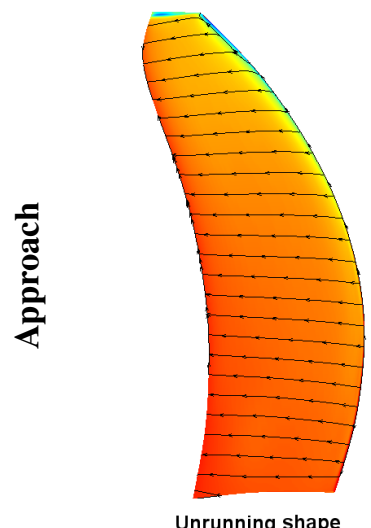

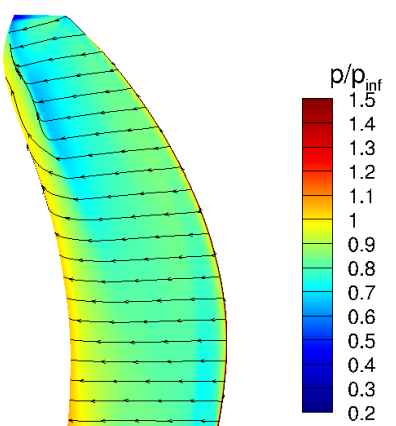

Running shape

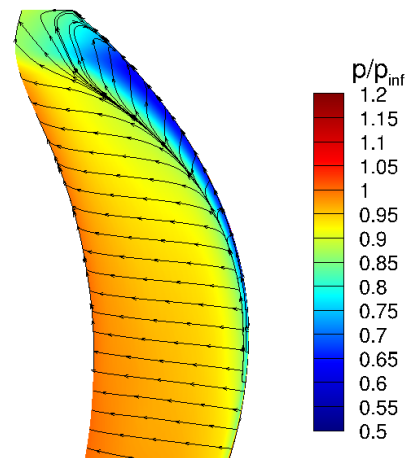

Running shape
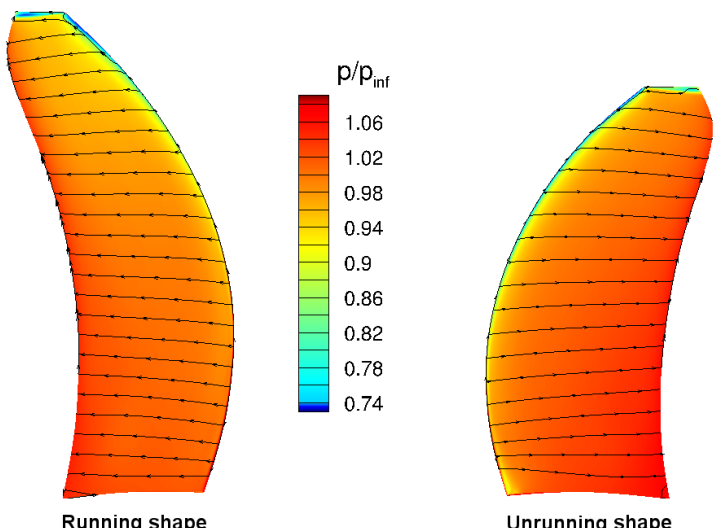

Unrunning shape
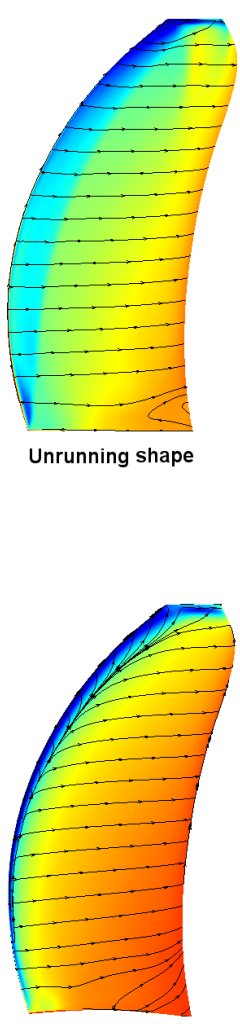

Unrunning shape
Rear rotor blade
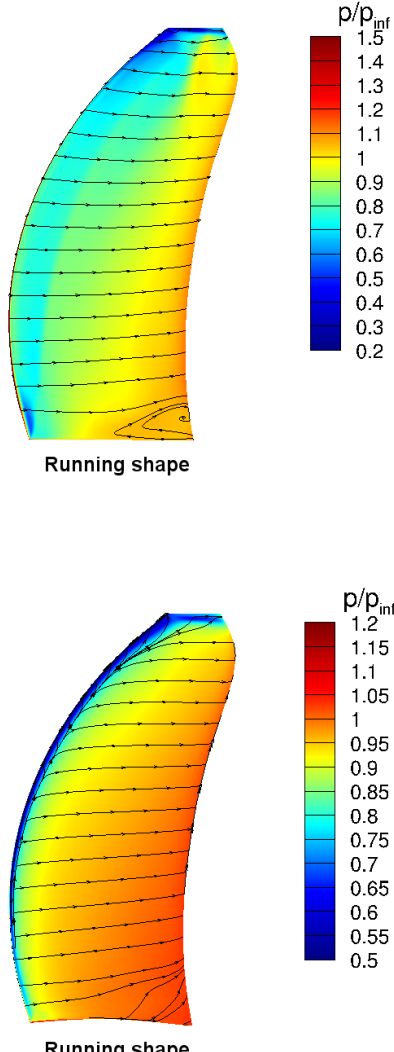

Running shape
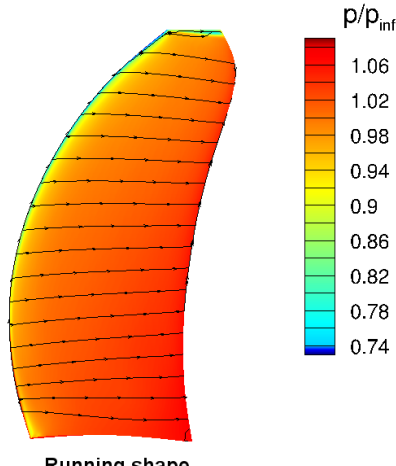

Figure 7. Time-averaged wall pressure and friction lines on blade suction-side for cruise, takeoff and approach operating points. 


\section{Front rotor blade}
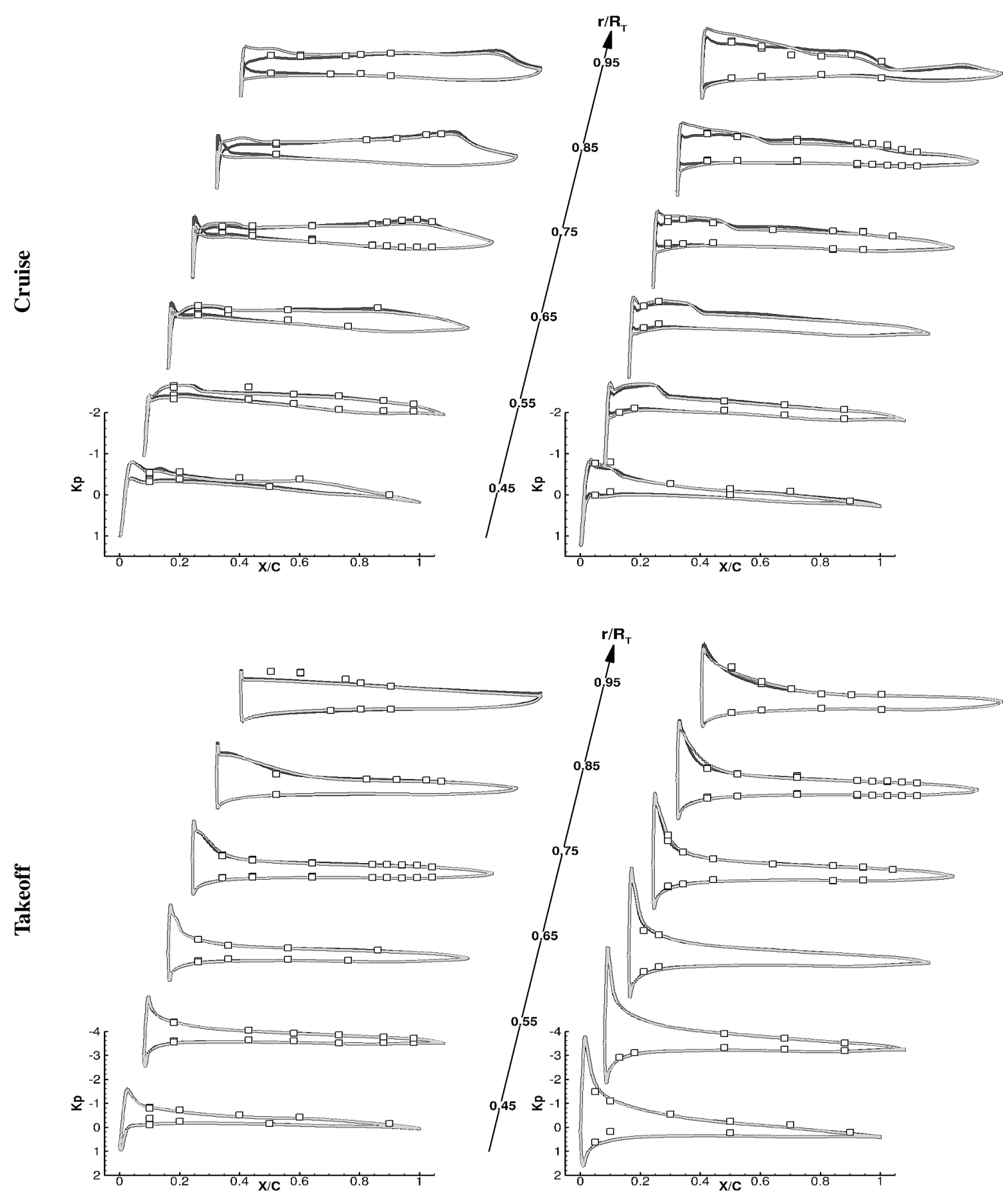

Figure 8. Comparison of computed and measured front and rear blade pressure coefficients for cruise, takeoff and approach operating points: unrunning shape $(-)$, running shape $(-)$, experiments $(\square)$.

Rear rotor blade 


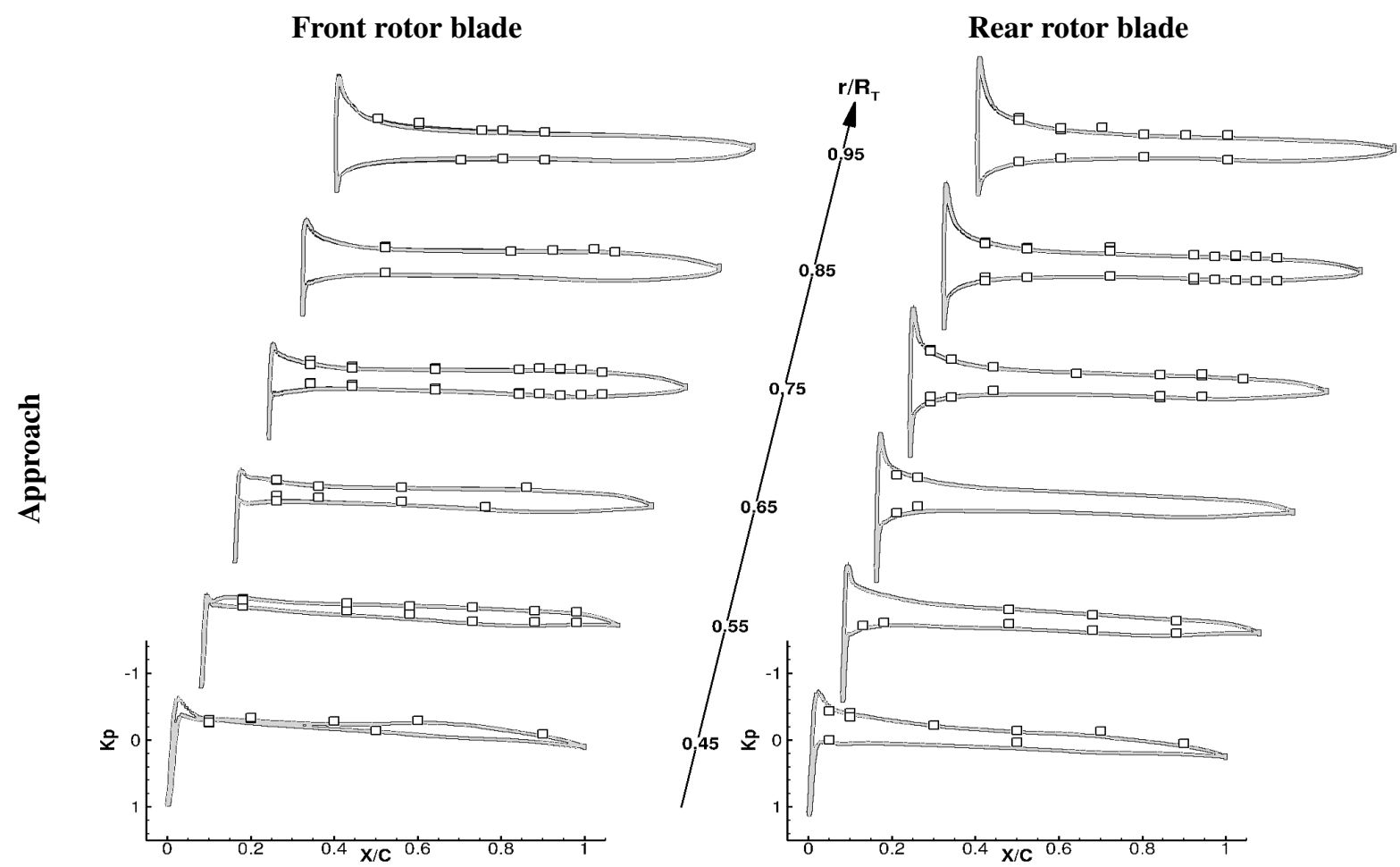

Figure 8. Comparison of computed and measured front and rear blade pressure coefficients for cruise, takeoff and approach operating points: unrunning shape (-), running shape (-), experiments $(\square)$ (continued).

\section{IV.D. Unsteady loads}

We focus now on unsteady loads that are of importance regarding vibrations and interaction noise. The time evolutions of the thrust coefficients of the front and rear rotor blades are displayed in Fig. 9 over a blade azimuth variation corresponding to the phase-lag period. The greatest fluctuations occur for the cruise operating point. This is true for both front and rear rotors. The second operating point with significant $C_{T}$ fluctuation is takeoff. Note that in terms of dimensional thrust fluctuations, takeoff and cruise operating points have amplitudes of the same order once the air density and rotation speed are taken into account. For the approach operating point, only the rear rotor exhibit noticeable thrust fluctuations.

The mode amplitudes of the Fourier transform of the front and rear rotor blade thrust coefficients are also displayed in Fig. 9. This data shows that for the cruise operating point, the amplitudes of the front rotor running shape are decreased for all interaction modes, except for the second one, when compared to the front rotor unrunning shape. For the rear rotor, the running shape ex- 
hibit lower amplitudes than the unrunning shape for the first, third and fifth interaction modes with the front rotor while the opposite happens for the second, fourth and sixth interaction modes. These differences may be due to the modifications of the front rotor potential field and wake but also to the modification of the rear blade response itself due to the change of flow topology between the unrunning and running shapes.

For the takeoff operating point, the front blade running shape exhibits higher amplitudes than the front blade unrunning shape for all interaction modes with the rear rotor. Considering the rear blade, the $C_{T}$ fluctuation amplitudes of the running shape are higher than those of the unrunning shape only for the first and third interaction modes.

Finally, for the approach operating point, both geometries are very close in terms of $C_{T}$ fluctuation mode amplitudes. Differences are observed mostly for the first interaction mode which has higher amplitude for the unrunning shape on the front rotor and higher amplitude for the running shape on the rear rotor. 
Front rotor blade
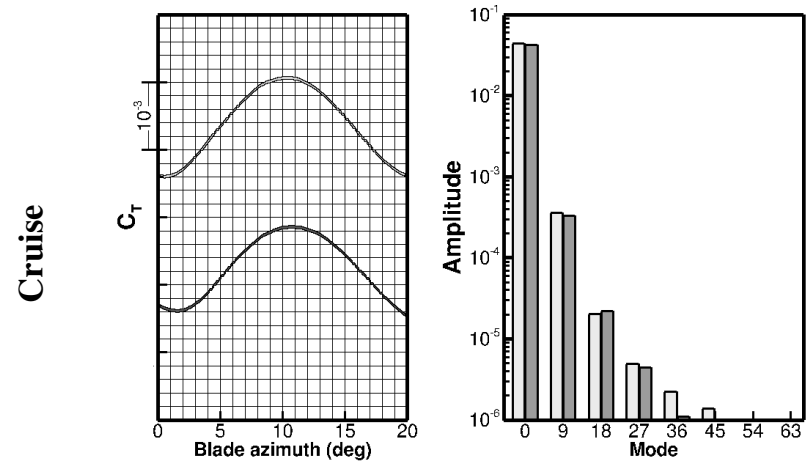

$\square$ Unrunning shape $\quad \square$ Running shape

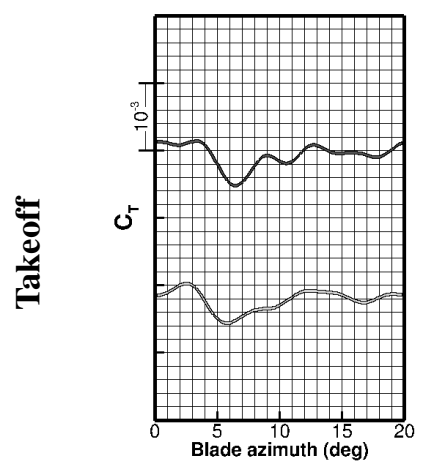

$\square$ Unrunning shape

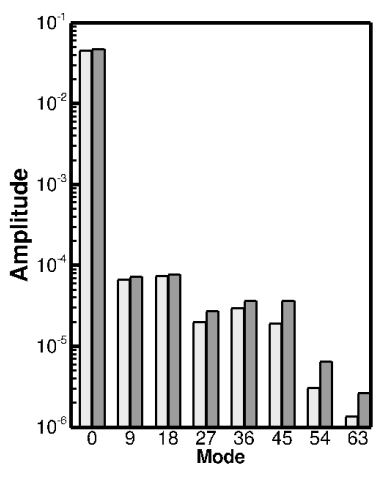

$\square$ Running shape
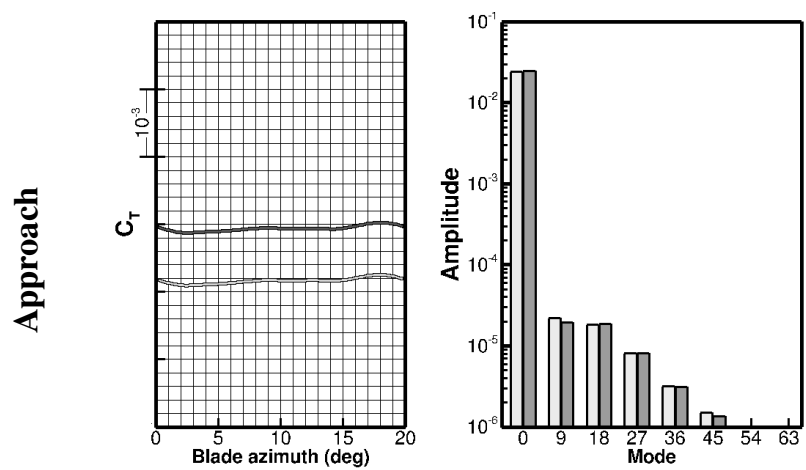

$\square$ Unrunning shape

$\square$ Running shape
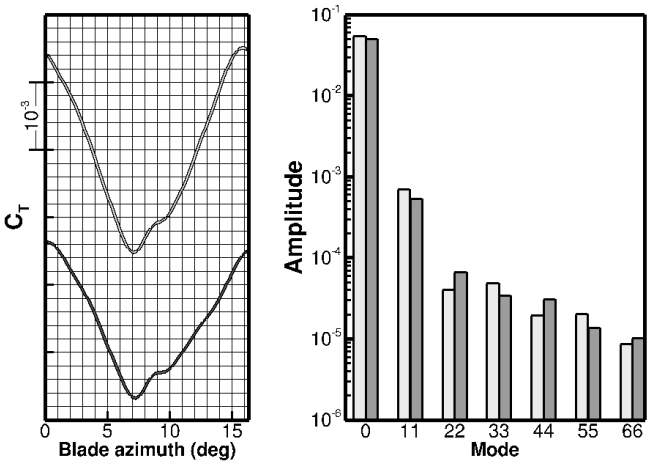

$\square$ Unrunning shape $\square$ Running shape
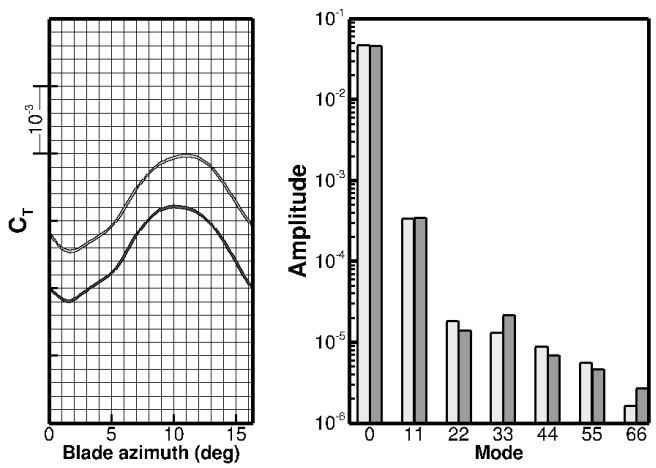

$\square$ Unrunning shape $\square$ Running shape
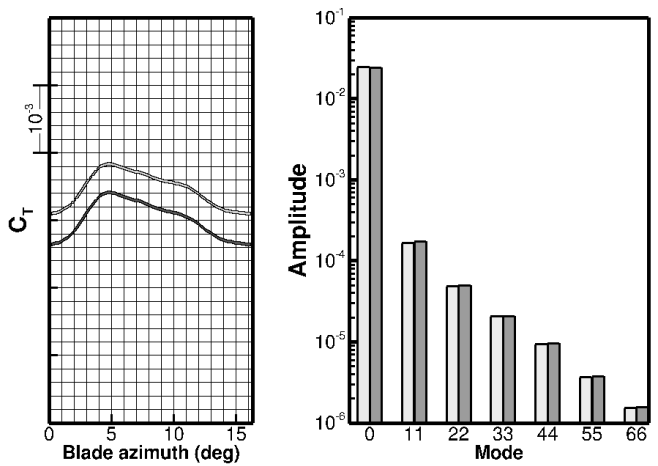

$\square$ Unrunning shape

$\square$ Running shape

Figure 9. Time-evolution over a chorochronic period and spectral decomposition of front and rear rotor blade traction coefficients for cruise, takeoff and approach operating points. 


\section{IV.E. Aeroacoustics}

\section{IV.E.1. Wind tunnel tests signal post-processing}

The acoustic signals from the Z49 experiments have been acquired by Z49 test teams (Airbus and ONERA) on a set of near field microphones distributed on a beam parallel to the rotors axis at $2.2 R_{t}$ (cf. Figure 2). For every operating point the signals were recorded during 30 seconds at a sampling frequency of $62.5 \mathrm{kHz}$ (see Figure 10 (a)). The Power Spectral Density (PSD) of each signal has been estimated with an averaged periodogram using the Welch method. ${ }^{41}$ In order to reduce the variance (i.e the noise) while keeping a fine frequency resolution, the signal is split into 50 segments of equal length, with 50\% overlapping, and a Hamming window is applied to each segment, leading to a frequency resolution of $0.84 \mathrm{~Hz}$. The Sound Pressure Level and directivities of the tones are then obtained by integrating the PSD around the theoretical tone frequencies deduced from the measured rotation speeds. The bandwidth used for this integration is $\pm 3.2 \mathrm{~Hz}$ for the cruise operating point and $\pm 2.5 \mathrm{~Hz}$ for the take-off and approach operating points. These margins were determined empirically in order to limit as much as possible the integration of broadband noise in the evaluation of the tones levels. Finally, considering the acoustic beam dimensions, a correction accounting for scattering effect is applied. This correction has been derived from Boundary Element Method numerical simulations, where an acoustic monopole source has been placed in the vicinity of the antenna, with various positions tested, and where the noise on the beam was computed at the microphone locations. These calculations allowed deriving a correction function depending on the wavelength, i.e. on the emitted frequency and the microphone location, which vary from 0 to about $-7 \mathrm{~dB}$. This post-processing has been validated against available results of a more time consuming but also more accurate Time Synchronous Averaging (TSA) method. The comparison of these two methods, illustrated in Figure 10 (b), gives differences lower than $1 \mathrm{~dB}$ as long as the tones emerge sufficiently from background and broadband noises.

Last but not least, no acoustic treatment of the wind tunnel was used for these high-speed and low-speed tests which means there may be wall reflections introducing a bias on the measured signals. These reflections have been quantified by Computational AeroAcoustics (CAA) simula- 


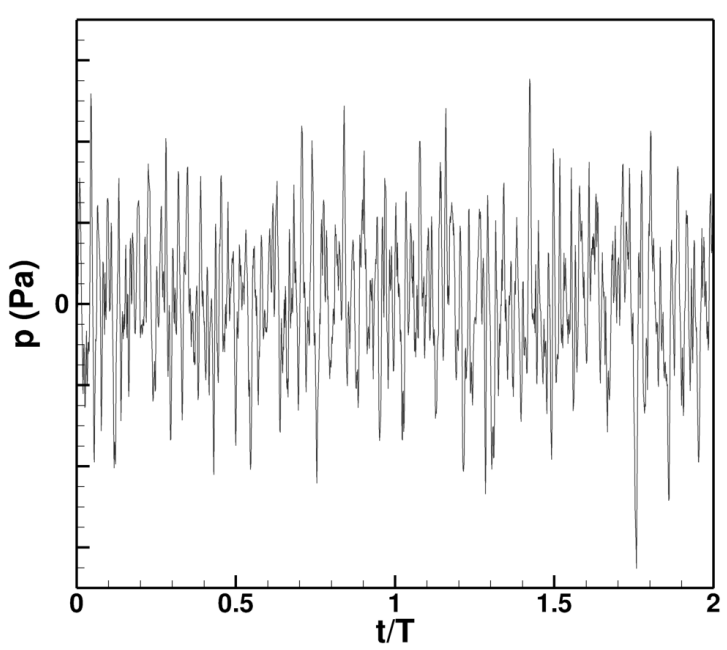

(a) Pressure signal over two front rotor periods

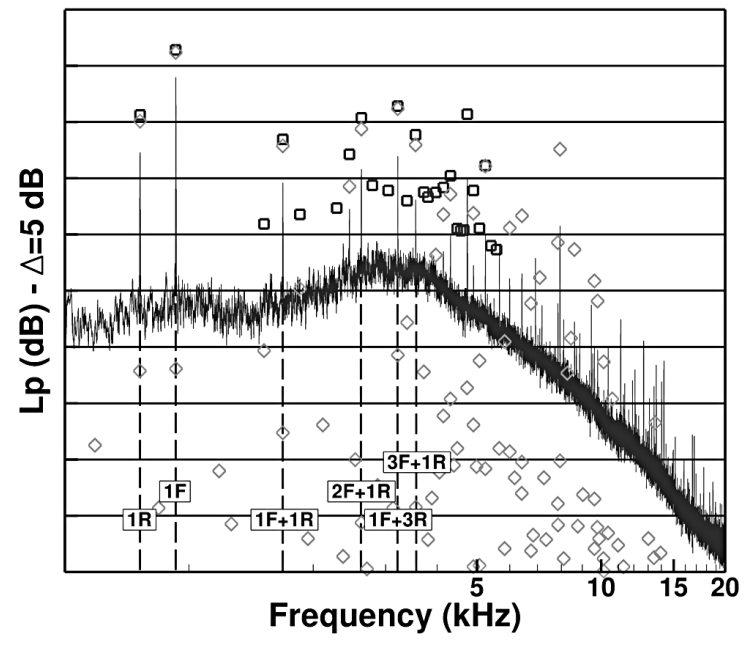

(b) Welch spectrum (-), integrated tones $(\square)$, and TSA spectrum $(\diamond)$

Figure 10. Signal analysis example at the take-off operating point, measured on the acoustic beam in the rotors plane

tions of monopoles rotating in the wind tunnel in a $M=0.75$ mean flow. At the acoustic antenna location, these reflections lead to important noise increases of the rotors fundamental tones and harmonics in the upstream and downstream directions, while the tones maximum level is decreased due to destructive interferences. These reflections are present as well on the interaction tones but are less harmful, since their levels are lower, and less acoustical energy is focused towards the lateral walls. For the low speed operating points, the lower acoustic energy mitigates the wind tunnel reflections impact on the measurements. All the above choices and imperfections regarding the experiments must be kept in mind, especially when comparing the measurements with the numerical simulations.

\section{IV.E.2. Noise directivities}

This section presents the noise directivites obtained from the FWH porous surface introduced in §III.C. The signals have been computed on locations corresponding to the wind tunnel tests near field microphones, in order to compare them with the measured ones. The antenna has also been virtually extended with additional upstream and downstream points, in order to cover directivity angles ranging from $10^{\circ}$ (upstream) to $170^{\circ}$ (downstream) in the frame of the rear rotor pitch 
axis. The tones are identified by the combinations of the Blade Passing Frequencies (BPF) of the front and rear rotors, respectively written $F$ and $R$. The Overall Sound Pressure Level (OASPL) is obtained by summing all the tones. Note that the plotted tones are not all the same depending on the operating point. Focus is first put on the dominating ones, and then on those illustrating at best the differences between the unrunning and running shapes, which generally differ from one operating point to another. Moreover, the tones for which the experimental measurements are the most reliable are preferably shown.

Several acoustic directivities for the cruise operating point are presented in Figure 11. On both rotors fundamental tones and their harmonics, the running shape geometries lead to small decreases. These lessenings are in agreement with the previous observations made on the mean values of both pressure and thrust coefficients. The area between suction and pressure sides pressure coefficients $K p$, which is responsible for this steady noise, is particularly decreased when considering the blades running shape at the tip (see Figure 8). It appears to be more pronounced on the front propeller than on the rear one, which explains the $2 \mathrm{~dB}$ decrease on the front rotor harmonics, while it is below $1 \mathrm{~dB}$ on the rear ones. However, it cannot be stated whether these noise reductions are in agreement with the experimental measurements, due to the reflections on the wind tunnel walls. Acoustic reflections seem to have less impact on the interaction tones, since the numerical simulations and the measurements are in better agreement. On these frequencies, the changes induced by the running blade geometries are clearly visible. It is characterized by noise small reductions or increases of the maximum levels depending on the tones and directivity angles. This is again in agreement with the modal analysis of the thrust coefficients, discussed in §IV.D, for which reductions or increases were observed depending on the harmonics.

For the take-off operating point, noise directivities are presented in Figure 12. As can be expected based on the mean values of the thrust coefficients, displayed in Figure 9, the front blade running shape leads to a slight increase of noise on the front rotor fundamental, about $1.5 \mathrm{~dB}$, while the rear one induces an even smaller decrease on the $1 R$ tone, lower than $1 \mathrm{~dB}$. The same behaviors are observed on their harmonics, which are not shown for brevity sake. For both rotors, taking into account the running shapes improves the comparison with the experimental results for 


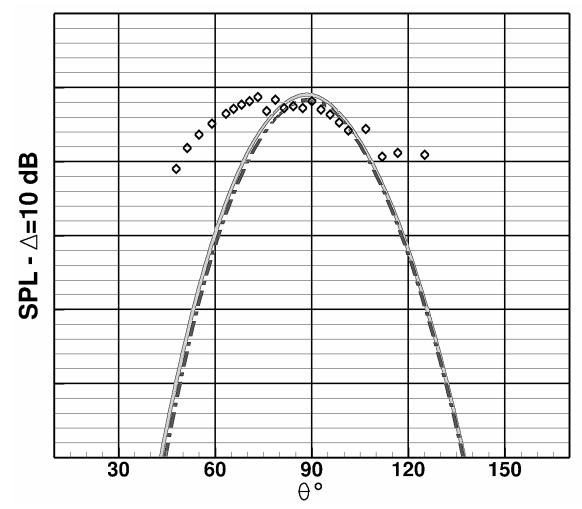

(a) $1 \mathrm{R}(9 \mathrm{n})$

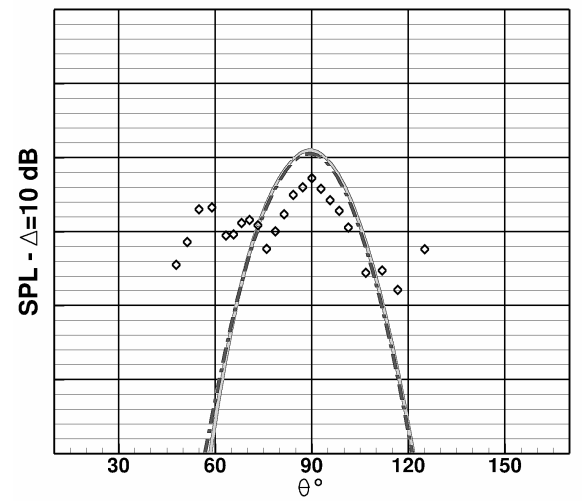

(c) $2 \mathrm{R}(18 \mathrm{n})$

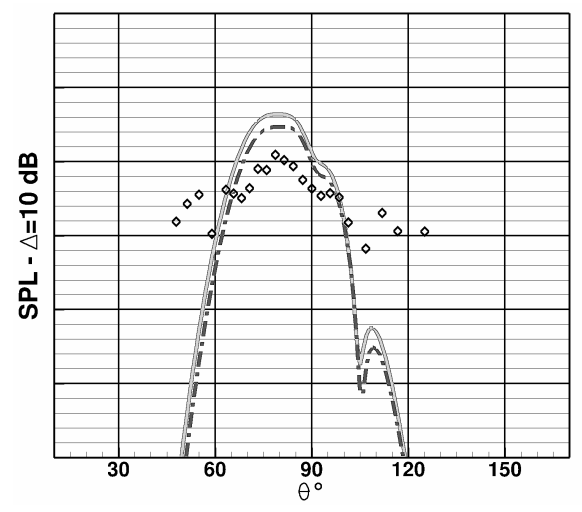

(e) $2 \mathrm{~F}(22 \mathrm{n})$

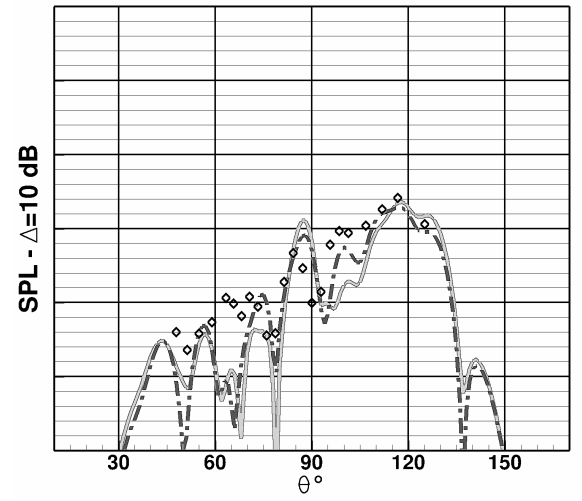

(g) $2 \mathrm{~F}+1 \mathrm{R}(31 \mathrm{n})$

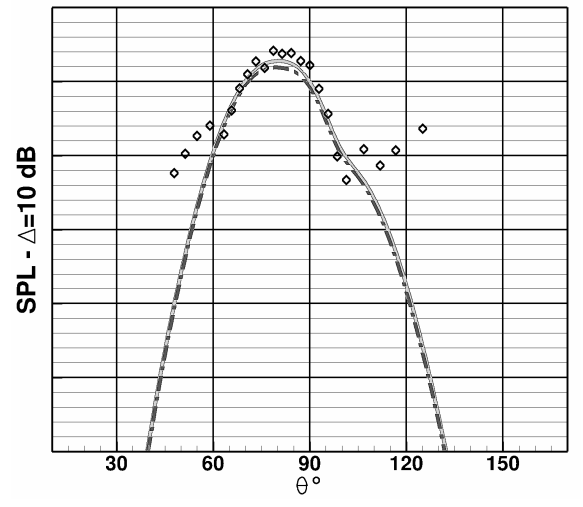

(b) $1 \mathrm{~F}(11 \mathrm{n})$

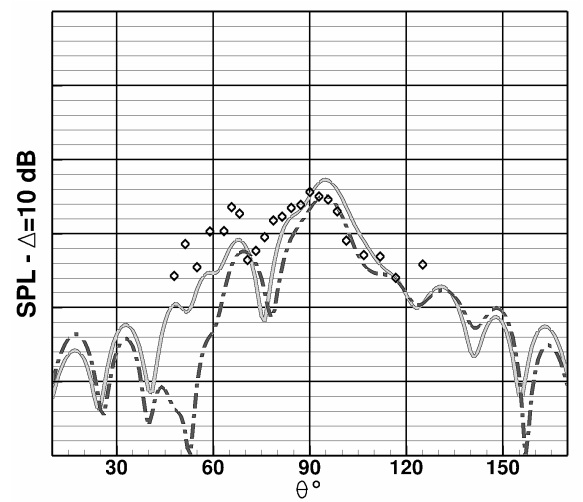

(d) $1 \mathrm{~F}+1 \mathrm{R}(20 \mathrm{n})$

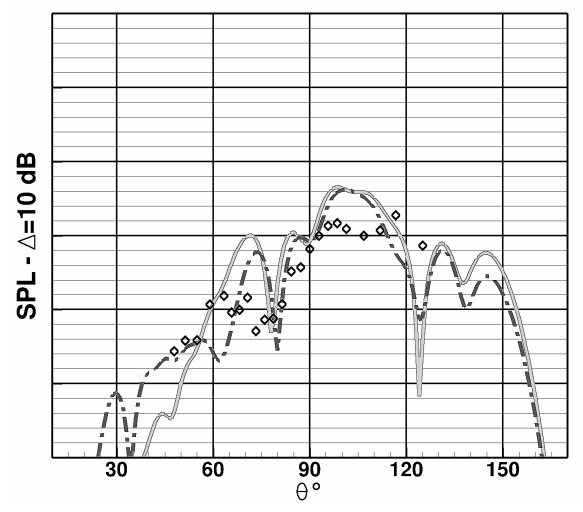

(f) $1 F+2 R(29 n)$

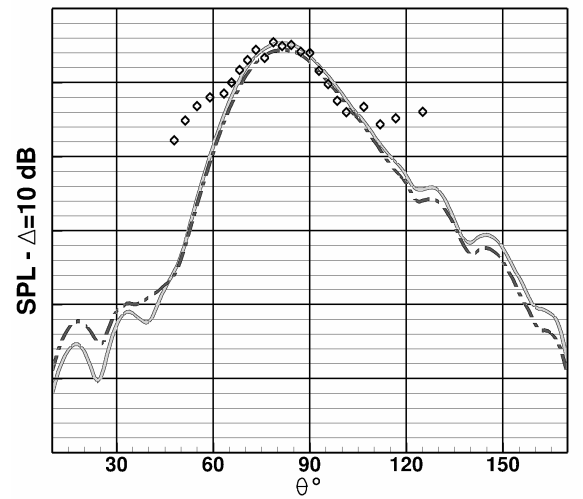

(h) OASPL

Figure 11. Cruise operating point: sound pressure level directivieisofieasured $(\diamond)$ and computed with unrunning $(-)$ and running (-- -$)$ blade shapes. 
observation angles without significant background noise levels, i.e. between $60^{\circ}$ and $110^{\circ}$, though the agreement with the unrunning shapes was already satisfying with gaps up to $2 \mathrm{~dB}$. Regarding the interaction tones, the directivity lobes are locally modified within a range of $-2 \mathrm{~dB}$ to $5 \mathrm{~dB}$ when considering the blade running shapes. Most of them are slightly increased, in agreement with the differences between unrunning and running shapes previously seen on the thrust coefficient modes. From a general point of view, both unrunning and running shape numerical results show similar directivity patterns and levels as those obtained experimentally.

Finally, the acoustic directivities for the approach operating point are presented in Figure 13. Not surprisingly, considering the steady and unsteady aerodynamic studies from §IV.C and §IV.D, the unrunning and running shapes acoustic results are very close, with differences below $1 \mathrm{~dB}$, except on the $2 F+1 R$ interaction tone. 


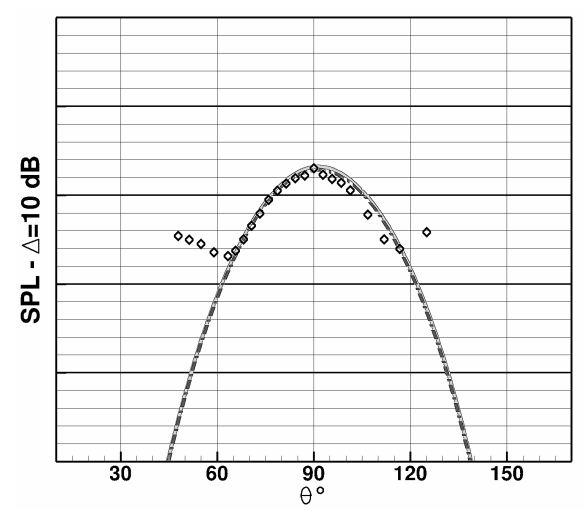

(a) $1 \mathrm{R}(9 \mathrm{n})$

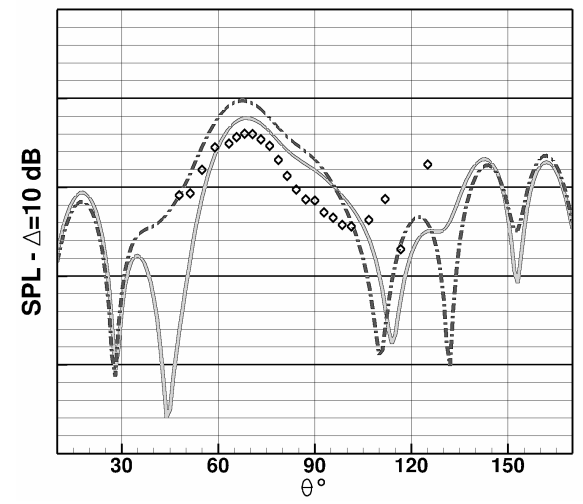

(c) $1 F+1 R(20 n)$

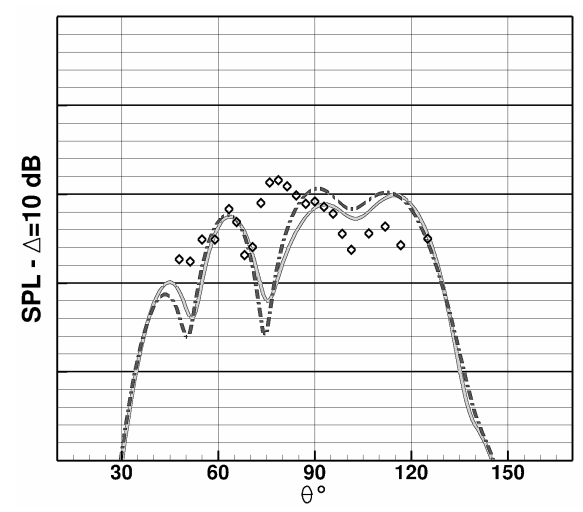

(e) $2 F+1 R(31 n)$

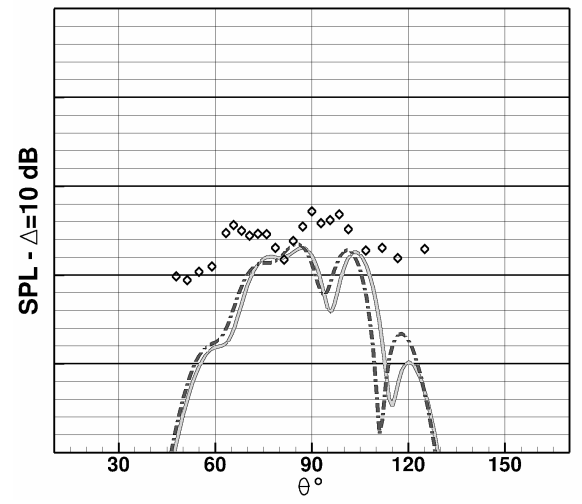

(g) $3 \mathrm{~F}+1 \mathrm{R}(42 \mathrm{n})$

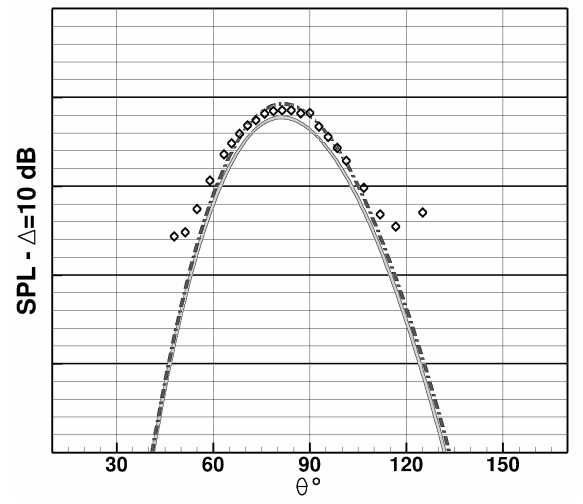

(b) $1 \mathrm{~F}(11 \mathrm{n})$

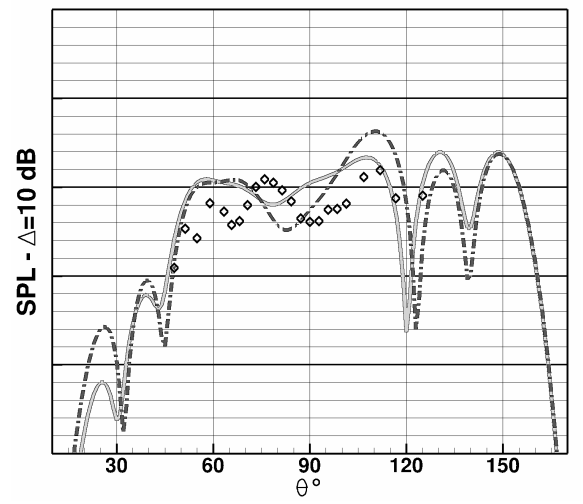

(d) $1 F+2 R(29 n)$

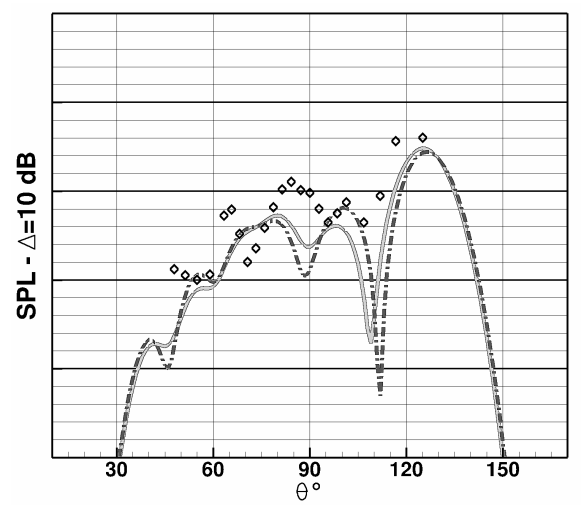

(f) $1 F+3 R(38 n)$

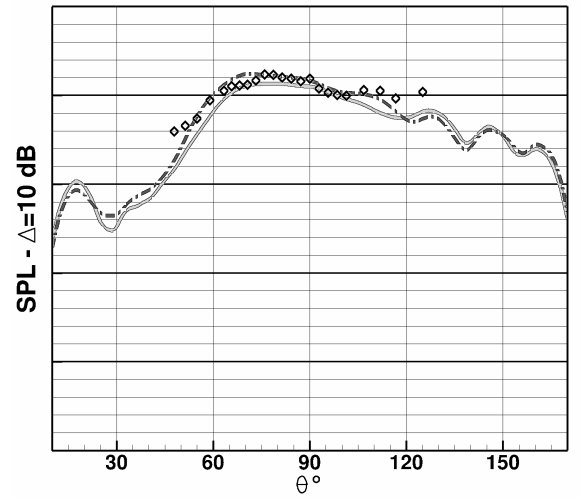

(h) OASPL

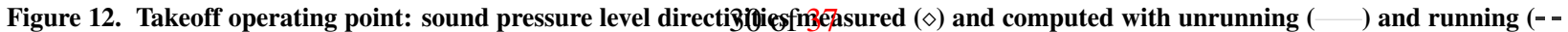
-) blade shapes. 


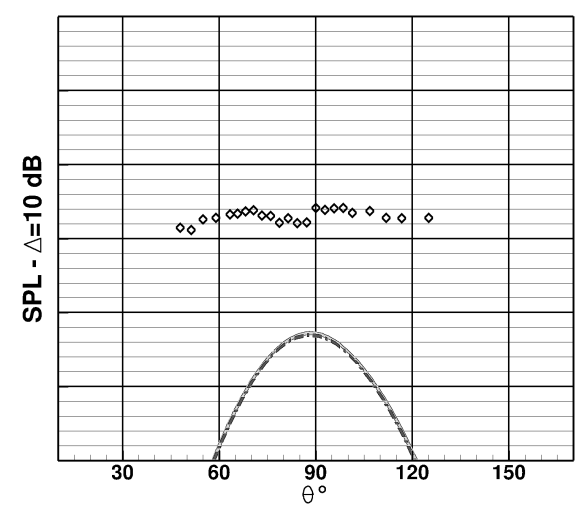

(a) $1 \mathrm{R}(9 \mathrm{n})$

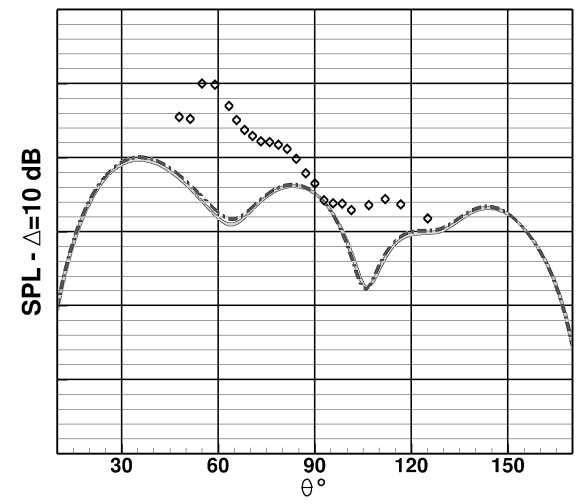

(c) $1 \mathrm{~F}+1 \mathrm{R}(20 \mathrm{n})$

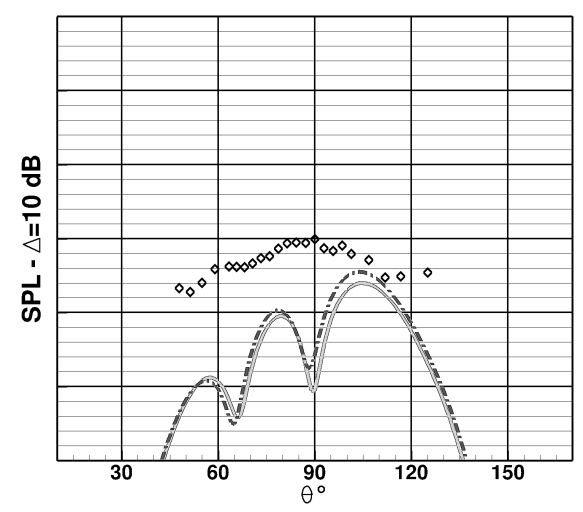

(e) $2 \mathrm{~F}+1 \mathrm{R}(31 \mathrm{n})$

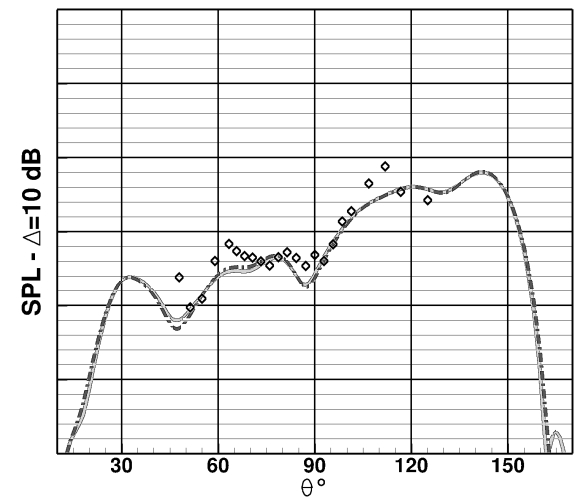

(g) $2 \mathrm{~F}+3 \mathrm{R}(49 \mathrm{n})$

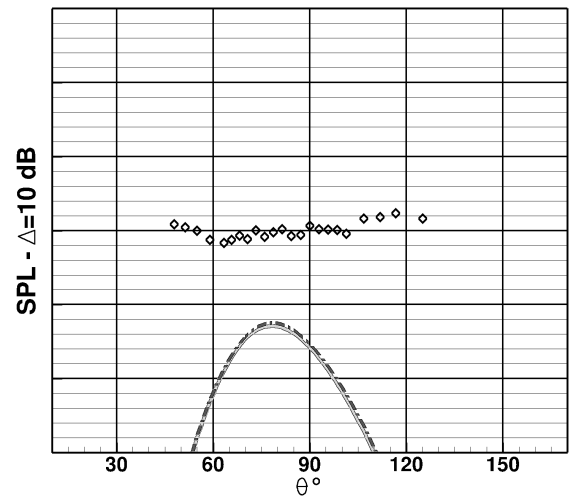

(b) $1 \mathrm{~F}(11 \mathrm{n})$

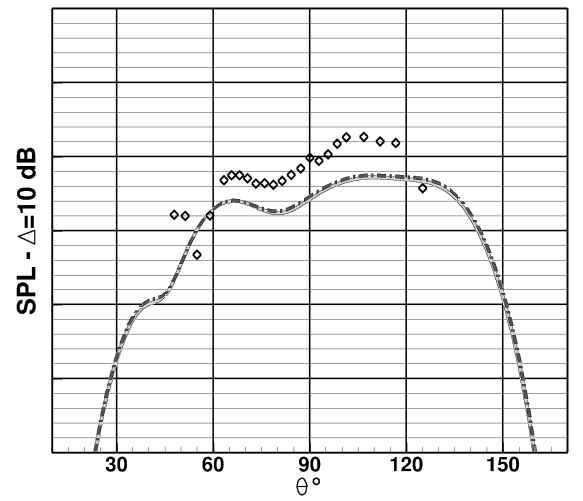

(d) $1 \mathrm{~F}+2 \mathrm{R}(29 \mathrm{n})$

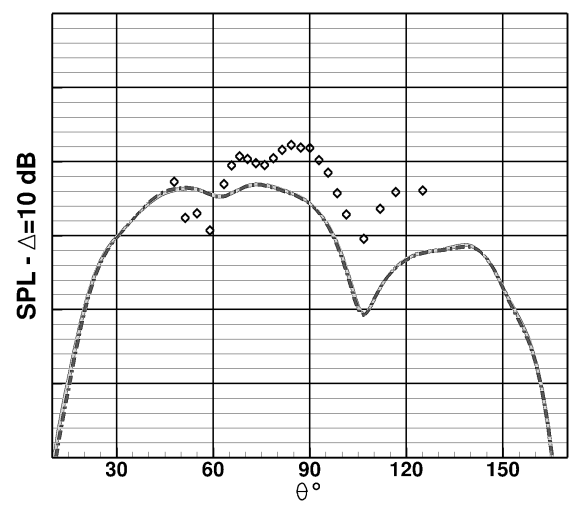

(f) $2 \mathrm{~F}+2 \mathrm{R}(40 \mathrm{n})$

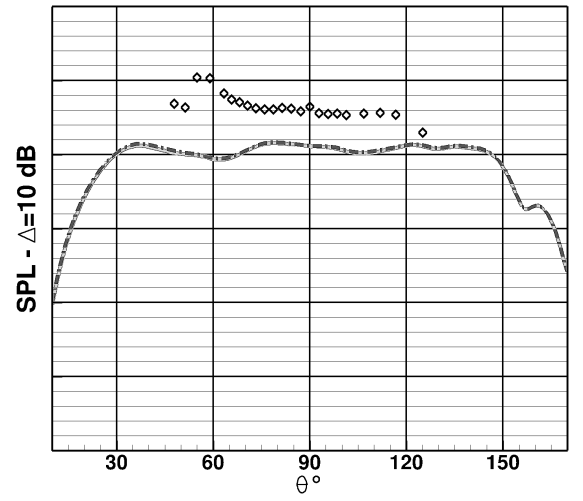

(h) OASPL

Figure 13. Approach operating point: sound pressure level direçividifs3measured $(\diamond)$ and computed with unrunning $(-)$ and running (--) blade shapes. 


\section{Conclusion}

A numerical study has been performed to quantify the influence of blade deformations on the aerodynamic and acoustic performances of an open rotor for different operating points. The open rotor considered in this study the Airbus Clean Sky generic Open Rotor configuration AI-PX7 for which blade deformations, aerodynamic and acoustic measurements were carried out on the $1 / 5^{\text {th }}$ scale Z49 model in ONERA's wind tunnel. The numerical analysis, based on the coupling of CFD with acoustic integral methods, has been performed for three operating points that are completely dissimilar in terms of aerodynamics and acoustics.

The first operating point considered is a high speed cruise condition at Mach number 0.75 characterized by moderate front and rear rotor thrusts, high tip Mach numbers, and high contribution of front and rear rotors self noise to the radiated noise. Inertial forces and aerodynamic loads results in an increase of the twist on the half upper section of the front rotor blades. Accounting for blade deformations reduces the errors on the predicted thrust and power from $7 \%$ and $8 \%$ respectively to $1 \%$ and $2 \%$ respectively. Acoustic predictions are slightly enhanced. Flow topology and flow physics remain very similar.

The second operating point addressed is a take-off condition at Mach number 0.2 , characterized by high values of front and rear rotor thrusts, moderated tip Mach numbers, and high contribution of interaction noise to the radiated noise. The deformations experienced by the blades are smaller in amplitude than for the high-speed condition but the variation of twist is of opposite sign so that running blade shapes are very dissimilar. The flow exhibits three dimensional separation at the leading edge of the front and rear rotor blades so that small deformations may have a significant impact on the open rotor aerodynamic performance. Contrarily to the high-speed case, accounting for blade deformation increases the front rotor thrust and power that were underestimated considering the unrunning shapes. The opposite happens for the rear rotor. Accounting for blade deformations reduces the errors on both predicted thrust and power from $2 \%$ to less than $1 \%$. The radiated noise computed with the running shape geometry is slightly higher but both self noise and interaction noise directivities remain very similar. 
The third operating point is an approach condition, characterized by low values of front and rear rotor thrusts, moderate tip Mach numbers, and high contribution of interaction noise to the radiated noise. The deformations experienced by the blades for this operating point are the smallest of this study. The aerodynamic results show discrepancies between the unrunning shapes and running shapes simulations of the same order than for the two other cases in terms of relative errors. Since the absolute values of thrust and power are rather low, these discrepancies are not so significant. Running and unrunning shape geometries exhibit same flow topology and acoustic computations show very similar results.

This study shows that accounting for blade deformations increases significantly the accuracy of CFD calculations. State of the art coupled aero-elastic computations compare well with experiments and should be used to predict open-rotor aerodynamic performance for multi-design point approaches. Yet, blade structure models are often not available when disruptive architectures are adressed. In this case, it would be better to use the manufactured blade shapes rather than the design blade shapes since the former kind of average the geometric and prediction discrepancies over extremely different operating points.

\section{Acknowledgement}

The authors acknowledge the Z49 Test Teams of Airbus Operation S.A.S. and ONERA for the experimental data. They especially thank Airbus for the rig development contribution and for the sharing of its AI-PX7 blade design. The research leading to these results has received fund-

ing from the European Union's Seventh Framework Programme (FP7/2007-2013) for the Clean Sky Joint Technology Initiative under Grant Agreement CSJU-GAM-SFWA-2008-001 and from H2020 Programme for the Clean Sky 2 Joint Technology Initiative under Grant Agreement CS2LPA-GAM-2016-2017-01. 


\section{References}

${ }^{1}$ Negulescu, C., “Airbus AI-PX7 CROR Design Features and Aerodynamics,” SAE Int. J. Aerosp., Vol. 6, No. 2, 2013, pp. 626-642.

${ }^{2}$ Khalid, S., Lurie, D., Breeze-Stringfellow, A., Wood, T., Ramakrishnan, K., Paliath, U., Wojno, J., Janardan, B., Goerig, T., Opalski, A., and Barrett, J., “Open Rotor Engine Aeroacoustic Technology CLEEN Project Final Report,” Tech. Rep. DOT/FAA/AEE/2014-04, GE Aviation, 2013.

${ }^{3}$ Srivastava, R., Sankar, N., Reddy, T., and Huff, D., “Application of an Efficient Hybrid Scheme for Aeroelastic Analysis of Advanced Propellers," 28 $8^{\text {th }}$ Aerospace Sciences Meeting, 8-11 January 1990, Reno, USA.

${ }^{4}$ Yamamoto, O. and August, R., "Structural and Aerodynamic Analysis of Large-Scale Advanced Propeller Blade," Journal of Propulsion and Power, Vol. 8, No. 2, 1992, pp. 367-373.

${ }^{5}$ Dunn, M. and Farassat, F., "High-Speed Propeller Noise Prediction - A Multidisciplinary Approach,” AIAA Journal, Vol. 30, 1992, pp. 1716-1723.

${ }^{6}$ Stürmer, A. and Akkermans, R., "Multidisciplinary analysis of CROR propulsion systems: DLR activities in the JTI SFWA project,” CEAS Aeronautical Journal, Vol. 5, 2014, pp. 265-277.

${ }^{7}$ Zachariadis, A., Brandvik, T., and Sohoni, N., "How to improve open rotor aerodynamics at cruise and take-off," Aeronautical Journal, Vol. 118, 2014, pp. 1103-1123.

${ }^{8}$ Envia, E., "Aeroacoustic analysis of a high-speed open rotor," International Journal of Aeroacoutics, Vol. 14, 2015, pp. 569-606.

${ }^{9}$ Séchaud, J.-F., "Development of a new rig with enhanced specifications for wind tunnel tests of isolated CROR propulsion systems," 30 th AIAA Aerodynamic Measurement Technology and Ground Testing Conference, 16-20 June 2014, Atlanta, Georgia.

${ }^{10}$ Méry, F., “S1MA High Speed Acoustic Measurement Devices for Open Rotor Mock Up,” $19^{\text {th }}$ AIAA/CEAS Aeroacoustics Conference, 27-29 May 2013, Berlin, Germany.

${ }^{11}$ Boisard, R., Falissard, F., Chelius, A., and Mauffrey, Y., "Effect of Blade Shape Accuracy on Counter Rotating Open Rotor Aerodynamics and Acoustics," 35 th AIAA Applied Aerodynamics Conference, 5-9 June 2017, Denver, USA.

${ }^{12}$ Cambier, L., Heib, S., and Plot, S., "The Onera elsA CFD software: input from research and feedback from industry," Mechanics \& Industry, Vol. 14, 2013, pp. 159-174.

${ }^{13}$ Prieur, J. and Rahier, G., "Aeroacoustic integral methods, formulation and efficient numerical implementation," Aerospace Science and Technology, Vol. 5, 2001, pp. 457-468.

${ }^{14}$ Lepot, I., Leborgne, M., Schnell, R., Yin, J., Delattre, G., Falissard, F., and Talbotec, J., “Aeromechanical opti- 
mization of a contra-rotating open rotor and assessment of its aerodynamic and acoustic characteristics," Proceedings of the Institution of Mechanical Engineers, Part A: Journal of Power and Energy, Vol. 225, 2011, pp. 850-863.

${ }^{15}$ Boisard, R., Falissard, F., and Delattre, G., "Assessment of aerodynamics and aero-acoustics tools for open rotors," $9^{\text {th }}$ European Turbomachinery Conference, 21-25 March 2011, Istanbul, Turkey.

${ }^{16}$ Giauque, A., Ortun, B., Rodriguez, B., and Caruelle, B., "Numerical error analysis with application to transonic propeller aeroacoustics," Computers and Fluids, Vol. 69, 2012, pp. 20-34.

${ }^{17}$ Colin, Y., Carazo, A., Caruelle, B., Nodé-Langlois, T., and Parry, A., "Computational strategy for predicting CROR noise at low speed, part I: review of the numerical methods," $18^{\text {th }}$ AIAA/CEAS Aeroacoustics Conference, 4-6 June 2012, Colorado Springs, USA.

${ }^{18}$ Colin, Y., Blanc, F., Caruelle, B., Barrois, F., and Djorjevic, N., "Computational strategy for predicting CROR noise at low speed, part II: investigation of the noise sources computation with the chorochronic approach," $18^{\text {th }}$ AIAA/CEAS Aeroacoustics Conference, 4-6 June 2012, Colorado Springs, USA.

${ }^{19}$ Colin, Y., Caruelle, B., and Parry, A., "Computational strategy for predicting CROR noise at low speed, part III: investigation of noise radiation with the Ffowcs Williams-Hawking analogy," 18 $8^{\text {th }}$ AIAA/CEAS Aeroacoustics Conference, 4-6 June 2012, Colorado Springs, USA.

${ }^{20}$ Boisard, R., Delattre, G., and Falissard, F., "Computational Fluid Dynamics as a Support to Counter-Rotating open-Rotor Wind-Tunnel Test Analysis," Journal of Aircraft, Vol. 51, No. 2, 2014, pp. 614-628.

${ }^{21}$ Delattre, G. and Falissard, F., "Influence of Torque Ratio on Counter-Rotating Open-Rotor Interaction Noise," AIAA Journal, Vol. 53, No. 9, 2015, pp. 2726-2738.

${ }^{22}$ Delattre, G., Falissard, F., Vion, L., and Jacquin, L., “Open rotor interaction noise reduction through front rotor wake modification,” International Journal of Aeroacoustics, Vol. 15, No. 1-2, 2016, pp. 207-227.

${ }^{23}$ Benoit, C., Péron, S., and Landier, S., "Cassiopee: A CFD pre- and post-processing tool," Aerospace Science and Technology, Vol. 45, 2015, pp. 272-283.

${ }^{24}$ Geeraert, A. and Stephan, C., "CROR Blade deformation, part 1: Experimental results by Strain Pattern Analysis," IFASD International Forum on Aeroelasticity and Structural Dynamics, June 28-July 2 2015, Saint Petersburg, Russia.

${ }^{25}$ Rougeault-Sens, A. and Dugeai, A., "NUMERICAL UNSTEADY AERODYNAMICS FOR TURBOMACHINERY AEROELASTICITY," UNSTEADY AERODYNAMICS, AEROACOUSTICS AND AEROELASTICITY OF TURBOMACHINES, edited by K. Hall, R. Kielb, and J. Thomas, Springer Netherlands, 2006, pp. 423-436.

${ }^{26}$ Wohlmuth, B., “A Mortar Finite Element Method Using Dual Spaces for the Lagrange Multiplier,” SIAM Journal on Numerical Analysis, Vol. 38, 2000, pp. 989-1012. 
${ }^{27}$ Erdos, I., Alzner, E., and Nally, W., "Numerical Solution of Periodic Flow Through a Fan Stage,” AIAA Journal, Vol. 15, 1977, pp. 1559-1568.

${ }^{28}$ Gerolymos, G., Michon, G., and Neubauer, J., "Analysis and application of chorochronic periodicity in turbomachinery rotor/stator interaction computations," Journal of propulsion and power, Vol. 18, No. 6, 2002, pp. 1139-1152.

${ }^{29}$ Wilcox, D., "Reassessment of the Scale-Determining Equation for Advanced Turbulence Models," AIAA Journal, Vol. 26, 1988, pp. 1299-1310.

${ }^{30}$ Menter, F., “Two-Equation Eddy-Viscosity Turbulence Models for Engineering Applications," AIAA Journal, Vol. 32, 1994, pp. 1598-1605.

${ }^{31}$ Zheng, X. and Liu, F., "Staggered upwind method for solving Navier-Stokes and $k-\omega$ turbulence model equations," AIAA Journal, Vol. 33, 1995, pp. 991-998.

${ }^{32}$ Jameson, A., Schmidt, W., and Turkel, E., "Numerical Solutions of the Euler Equations by Finite Volume Methods Using Runge-Kutta Time-Stepping Schemes,” AIAA Paper 81-1259, 1981.

${ }^{33}$ Martinelli, L. and Jameson, A., "Validation of a Multigrid Method of the Reynolds Averaged Equations," $26^{\text {th }}$ Aerospace Sciences Meeting, 11-14 January 1988, Reno, USA.

${ }^{34}$ Jameson, A., “Time Dependent Calculations Using Multigrid, with Applications to Unsteady Flows Past Airfoils and Wings," AIAA $10^{\text {th }}$ Computational Fluid Dynamics Conference, June 24-26, 1991, Honolulu, USA.

${ }^{35}$ Ffowcs Williams, J. and Hawkings, D., "Sound Generation by Turbulence and Surfaces in Arbitrary Motion," Philosophical Transactions of the Royal Society, Vol. A264, 1969, pp. 321-342.

${ }^{36}$ Rahier, G., Prieur, J., Vuillot, F., Lupoglazoff, N., and Biancherin, A., "Investigation of Integral Surface Formulations for Acoustic Post-Processing of Unsteady Aerodynamic Jet Simulations," Aerospace Science and Technology, Vol. 8, No. 6, 2004, pp. 453-467.

${ }^{37}$ Rahier, G., Huet, M., and Prieur, J., "Additional terms for the use of Ffowcs Williams and Hawkings surface integrals in turbulent flows," Computers \& Fluids, Vol. 120, 2015, pp. 158-172.

${ }^{38}$ Mauffrey, Y., Geeraert, A., and Verley, S., “Comparison between coupled CFD/CSM hot shape prediction and AIPX-7 CROR experimental data," 35 th AIAA Applied Aerodynamics Conference, 5-9 June 2017, Denver, USA.

${ }^{39}$ Stuermer, A. and Akkermans, R., "Validation of Aerodynamic and Aeroacoustic Simulations of Contra-Rotating Open Rotors at Low-Speed Flight Conditions," 32 ${ }^{\text {nd }}$ AIAA Applied Aerodynamics Conference, 16-20 June 2014, Atlanta, Georgia.

${ }^{40}$ Giez, J., Vion, L., Roger, M., Yakhina, G., and Moreau, S., "Effects of Intermittency and Geometry on the Turbulence Impingement Noise of a CROR Rear-Rotor Blade," 23 ${ }^{\text {rd }}$ AIAA/CEAS Aeroacoustics Conference, 5-9 June 2017, Denver, USA.

${ }^{41}$ Welch, P., "The Use of Fast Fourier Transform for the Estimation of Power Spectra: A Method Based on Time 
Averaging Over Short, Modified Periodograms," IEEE Transactions on Audio and Electroacoustics, Vol. AU-15, 1967, pp. 70-73. 